\title{
استخلام استراتيجية السقالة التعليمية في تنمية عادات العقل المنتجة لدى طلاب المرحلة الثانوية فى مادة الريـاضيات
}

\author{
إعداد \\ أ/ محمد جادالكريم عبدالعظيم محمود \\ باحث للرجة الماجستيز - بقسم المناهج وطرق تدريس الرياضيات

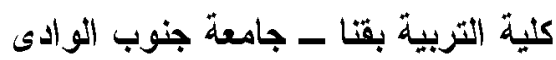

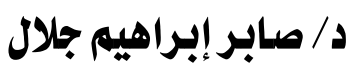 \\ أ.د / سلسامع أ حمد محمد جعفر ريحاز \\ المدرس بقم المناهج وطرق التخريس \\ الأستاذ المتفرغ بقسم المناهج وطرق التناريس \\ كلية التربية بقنا ـ جامعة جنوب الوادى لكائ \\ كلية التربية بقتا ـ جامعة جنوب الو الى الفى
}


استخدام استر اتيجية السقالة التعليمية في تنمية عادات العقل المنتجة لدى طلاب المرحلة الثانوية

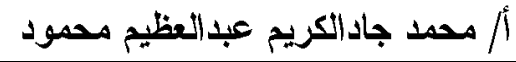

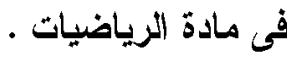

\title{
استخدام استراتيجية السقالة التعليمية في تنمية عادات العقل المنتجة للىى طلاب المرحلة الثانوبة فى مادة الريـاضيات
}

\author{
إعلاد - - اد \\ أ/ محمل جادالكريبم عبلدالعظيم محمود \\ باحث للرجة الماجستير - بقسم المناهج وطرق تكريس الرياضيات \\ كلية التربية بقنا - جامعة جنوب الو ادى الثى \\ أ.د / سامح أحمد محمد جمفر ريحاز \\ الأستاذ المنفرغ بقسم المناهج وطرق التذريس

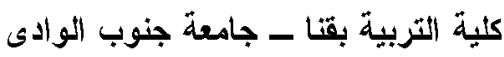

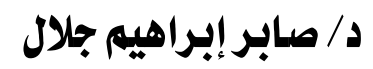

المدرس بقم المناهج وطرق التصريس

كلية التربية بقنا - جامعة جنوب التوادى الثى

المستخلص : (الم:

هدف البحث: تعرف أثر استخدام استراتيجية السقالة التعليمية في تتمية عادات العقل المنتجة

لأى طلاب الصف الأول الثانوى، وتتحصر مشكلة البحث فى تدنى مستوى الطلاب فى عادات

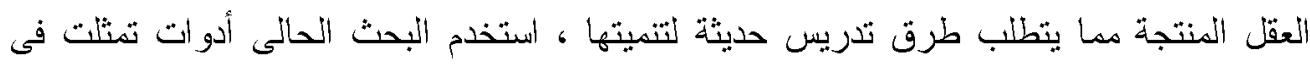

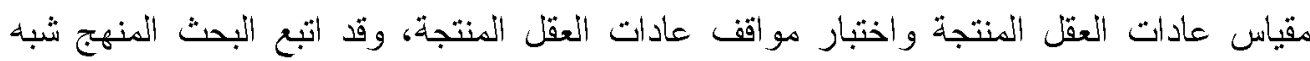
التجريبى من خلال تطبيق تدريس وحدات (المصفوفات، المتجهات، حساب المثلثات) باستخدام

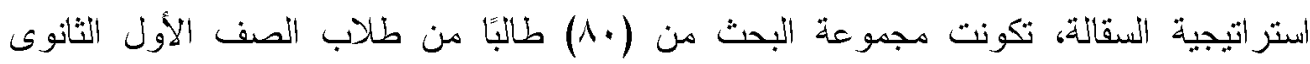

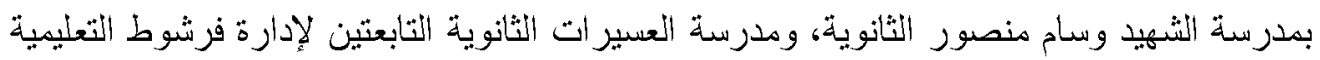

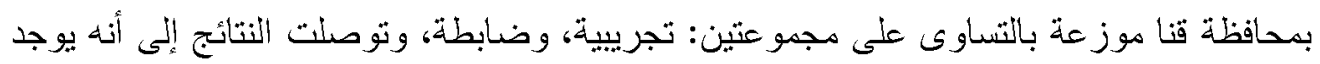

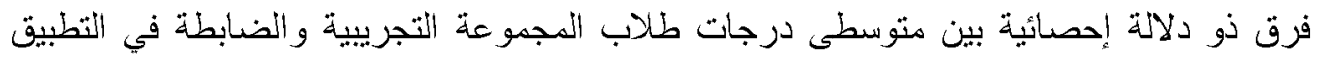

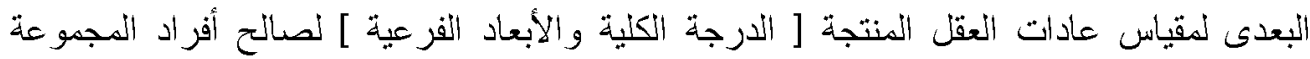
التجريبية ويوجد فرق ذو دلالة إحصائية بين متوسطى درجات طلاب المجموعة التجريبية

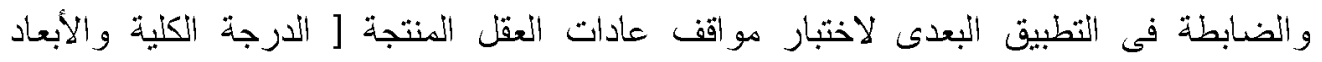
الفرعية] لصالح أفر اد المجمو عة التجريبية. الكلمات المفتاحية: استراتيجية السقالة التعليمية، عادات العقل المنتجة. 
استخدام استر اتيجية السقالة التعليمية في تنمية عادات العقل المنتجة لدى طلاب المرحلة الثانوية

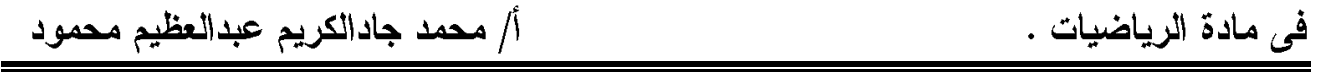

\title{
Using Educational Scaffolding Strategy in Developing The Productive Habits of Mind of Secondary Stage Students in Mathematics
}

\author{
Prepared by \\ Mohamed GadEl-Karem AbdEl-Azem Mahmoud \\ Researcher for master's degree in the department of \\ curriculum and methods of teaching mathematics \\ Faculty of Education of South Valley University
}

\begin{abstract}
:
The research aimed to know the effect of using educational scaffolding strategy on developing productive habits of mind among first-grade secondary students. The research problem is limited to the students 'low level of productive habits of the mind, which requires modern teaching methods for their development. The current research used tools represented in a scale of productive habits of mind and a test of the attitudes of productive habits of mind, and the research followed the quasi-experimental approach by applying the teaching of units (matrices, vectors, trigonometry) using the scaffold strategy, and the research sample consisted of (80) students from The first secondary school is in the Al-Shaheed Wissam Mansour Secondary School and the Al-Asirat Secondary School of the Farshout Educational Administration in Qena Governorate, distributed equally into two experimental and control groups. The research came to some results as there are:There are statistically significant differences between means of scores of the experimental and control groups in the post test of the productive habits of mind scale (whole mark - dimensions ) in favor of the experimental one.There are statistically significant differences between means of scores of the experimental and control groups in the post test of the attitudes of productive habits of mind test (whole mark - dimensions) in favor of the experimental one.
\end{abstract}

Key words: Educational Scaffolding Strategy, productive habits of mind. 
استخدام استر اتيجية السقالة التعليمية في تنمية عادات العقل المنتجة لاى طلاب المرحلة الثانوية

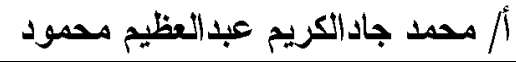

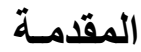

يتسم عصرنا الحالى بالتقام العلمى المتلاحق فى جميع المجالات، الذى ساهم فى إحداث كثير من التحو لات والتغيرات فى شتى ميادين الحياة المختلفة، ما ينطلب إعداد أجيال على قدر

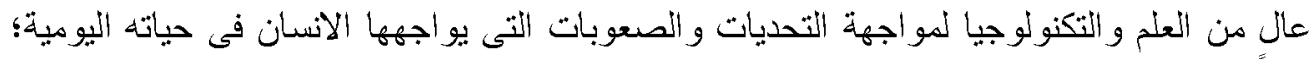

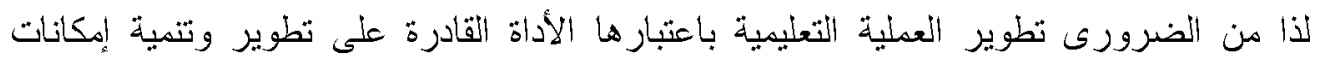

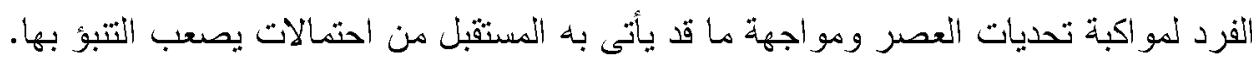
تواجه التربية على مستوى العالم تحديات كثيرة متعددة، ومتسار عة، وذلك نتيجة التغيرات

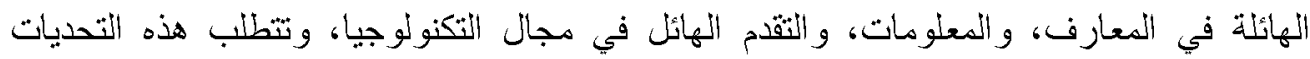

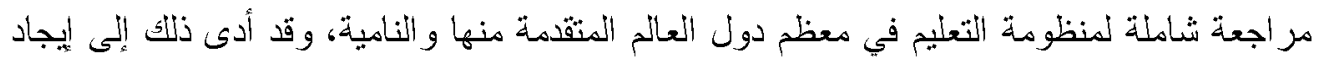

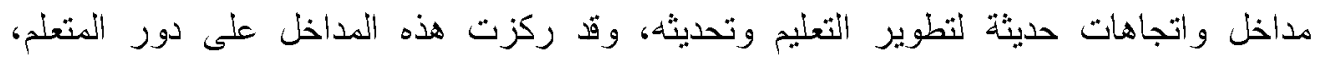

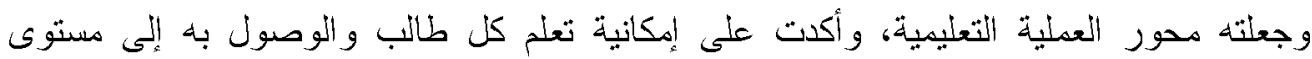

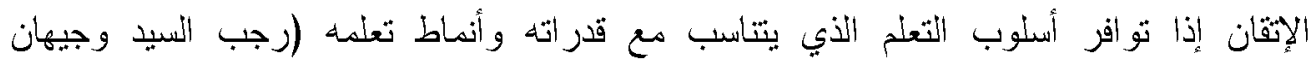

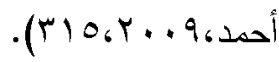

فألمتعلم فى عصر الانفتاح المعرفى يجب أن يتميز بالقدرة على الملاحظة، والقياس،

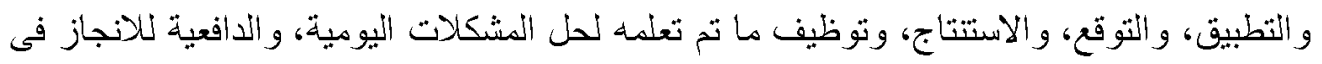

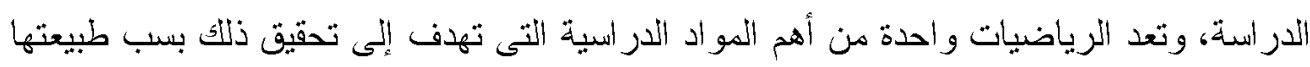

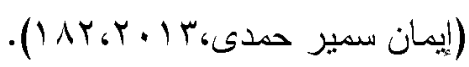

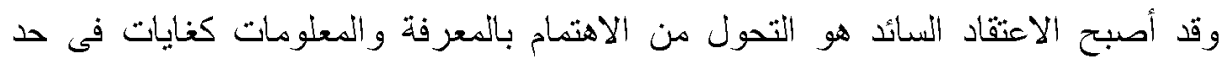

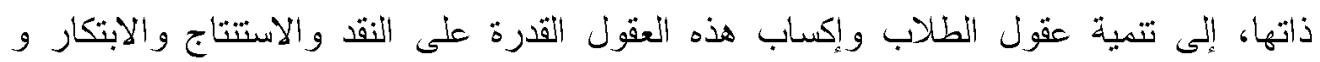

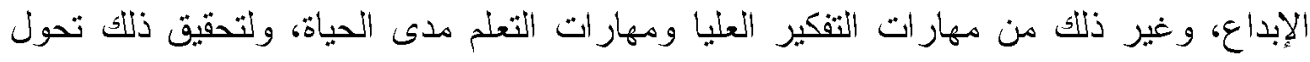

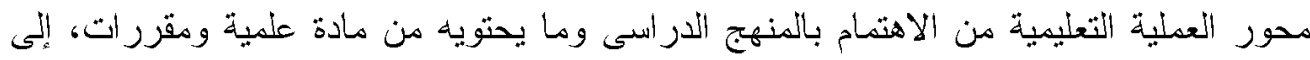

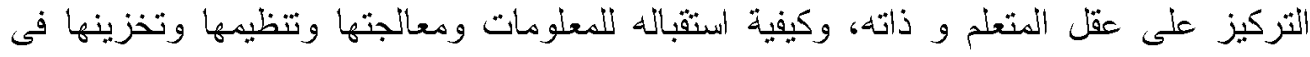
الذاكرة طويلة الأجل بحيث تصبح سهلة التذكر والتطبيق ( رجب النسيد و و جيهان

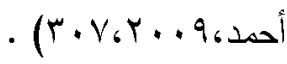

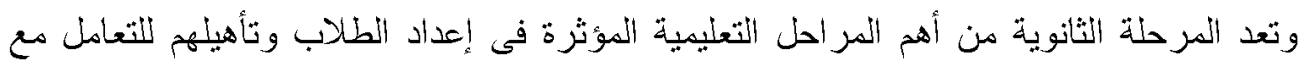

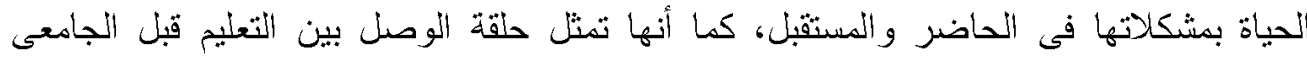

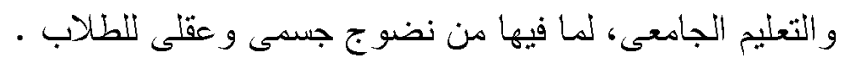

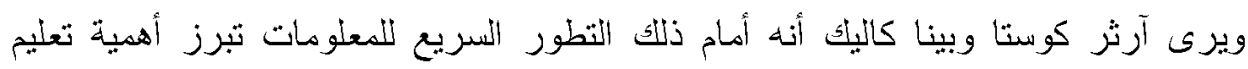

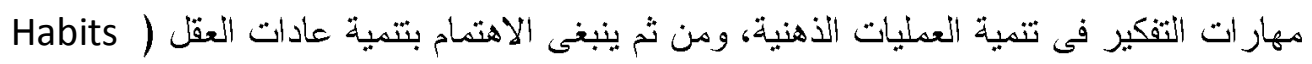


استخدام استر اتيجية السقالة التعليمية في تنمية عادات العقل المنتجة لاى طلاب المرحلة الثانوية

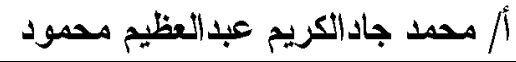

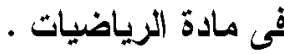

(of Mind

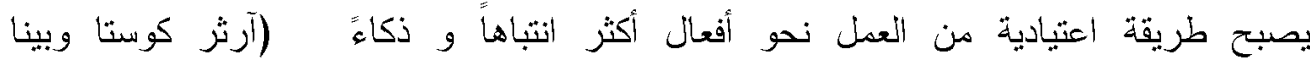
كاليك، r..

وقدم " كوستا " و" كاليكا " نموذجًا عامًا لعادات العقل، وتكــون هـــا النمــوذج مسن سـتة

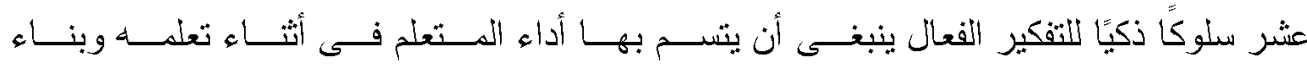

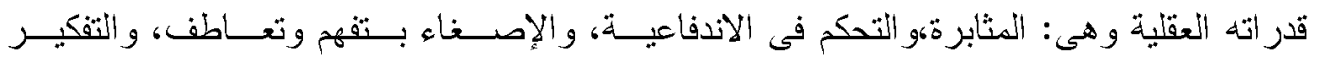

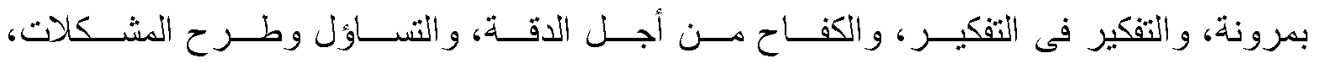

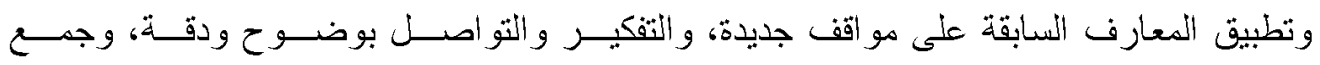

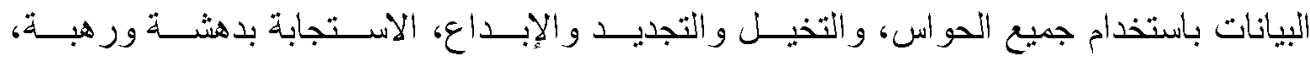

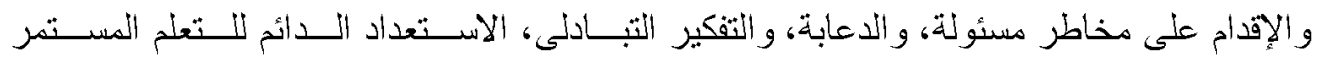
.(Costa \&Kallick,2008,18-37)

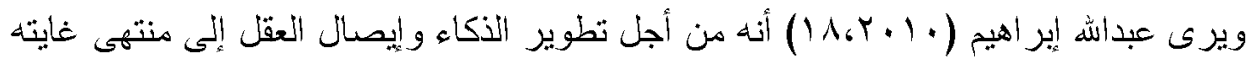

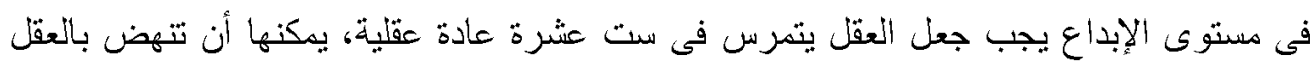

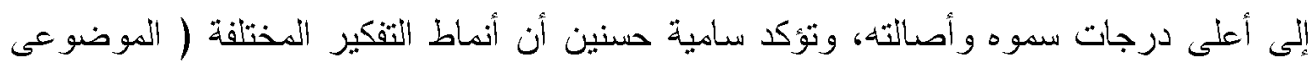

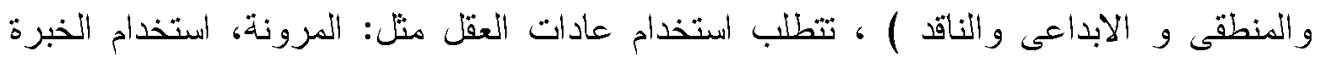

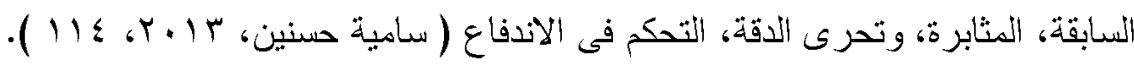

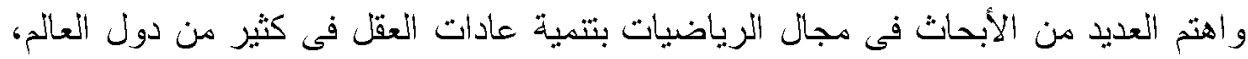

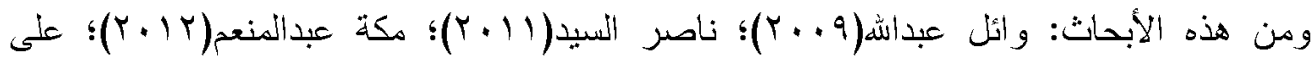

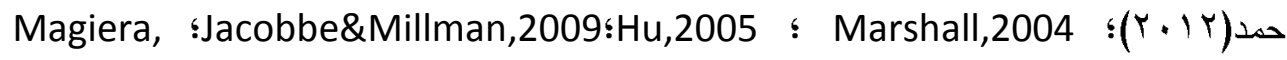

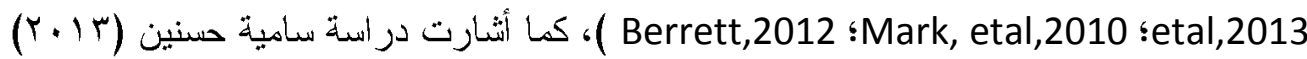
ودراسة عانثور محمد (Y.10) إلى ضرورة تنمية عادات العقل فى نعليم وتعلم الرياضيات

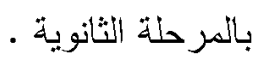
وفي قلب التغبرات التربوية و العلمية و التقنية النريعة اتجهت الأنظار نحو النظم التربوية، ومؤسساتها المختلفة، لتتهض بمسؤوليتها في بناء الفرد وفق منظور نزبوي منكامل، هدفه مساعدة

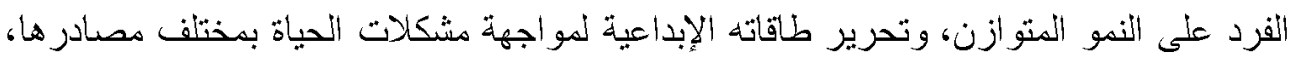

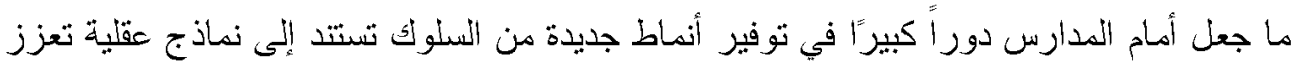
تعليم التفكير (خالد محمد،ه ه. . ب، (1).

وأمام ذللك التطور السريع للمعلومات تبرز أهمية تعليم مهار ات التفكير في تتمية العمليـات التهات

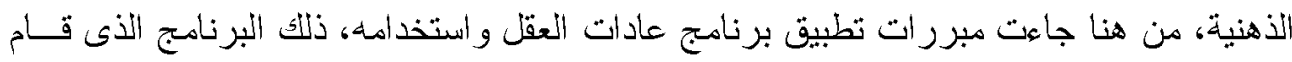


استخدام استراتيجية السقالة التعليمية في تنمية عادات العقل المنتجة لدى طلاب المرحلة الثانوية

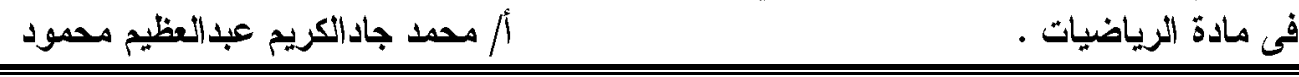

بتأليفه كل من آرثر كوستا و بينا كاليك و أطلقا عليه اسم عادات العقل، مشيرين بذلك إلى أن سلوك

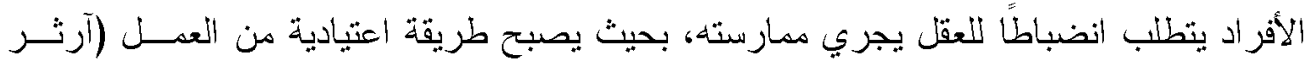

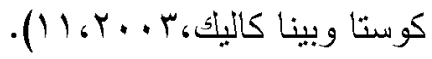

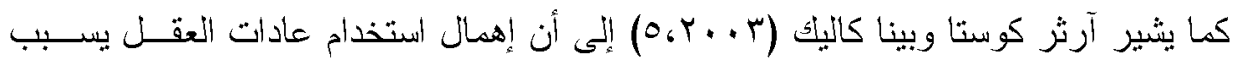

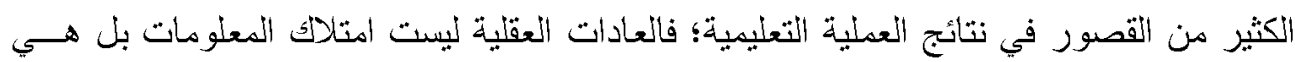

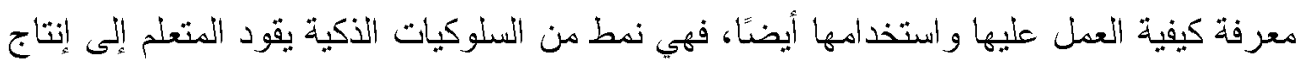

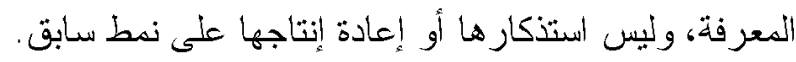

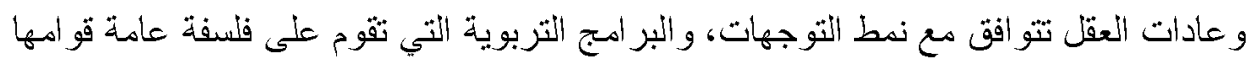

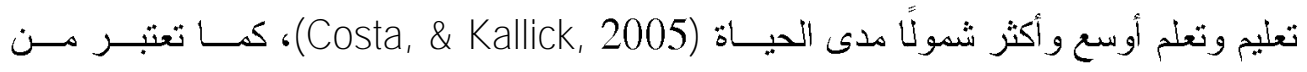

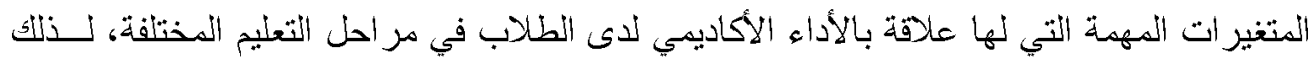

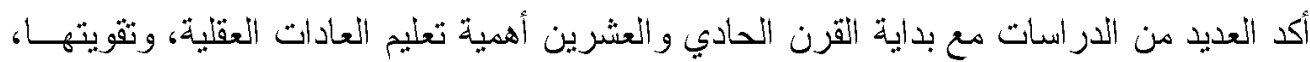

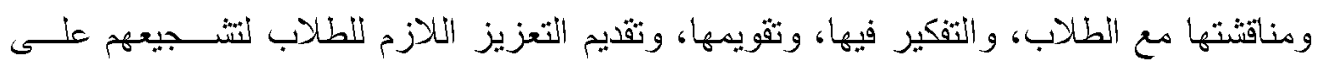

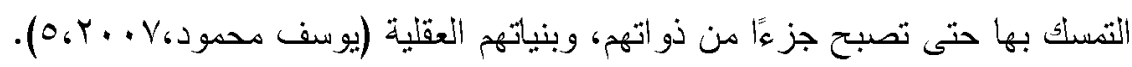

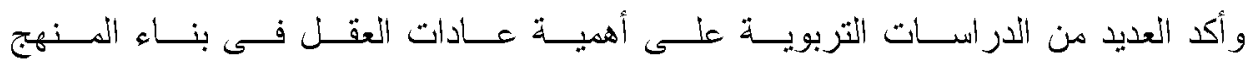

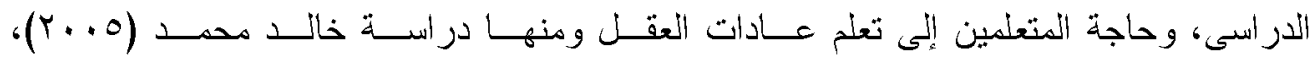

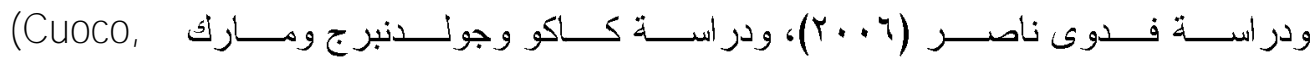

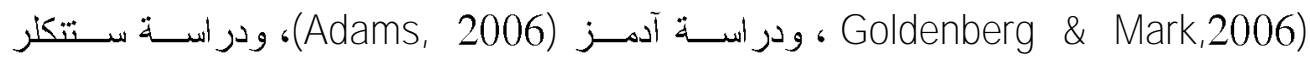

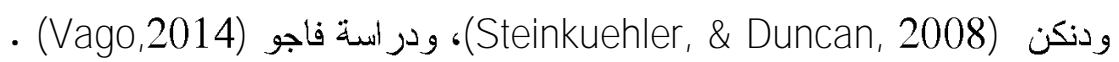
ومما يؤكد أهمية عادات العقل وعلاقتها بالرياضيات اتجاه العديد من الدراسات إلى تتميتها

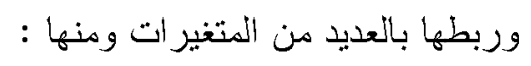
• دراسة LeiKin Roza (2007) : و التى أوضحت مدى الارتباط بين عادات العقل :

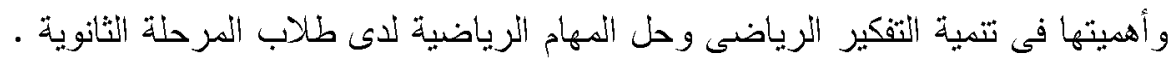

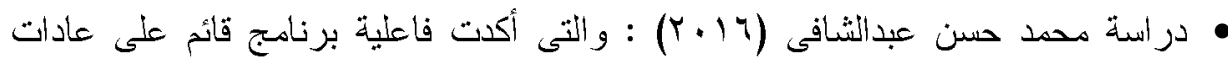

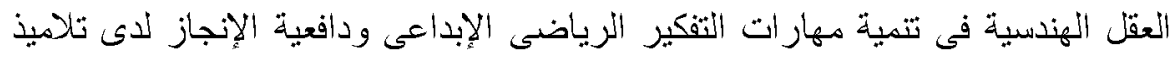
المرحلة الإعدادية.

مراسة فايز محمد هنصور (Y.Y.Y) : أوضحت وجود علاقة ارثباطية ذات دلالة

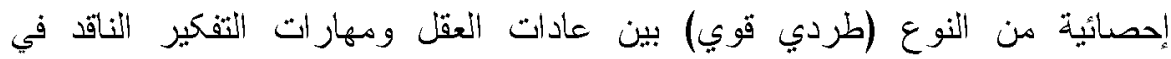

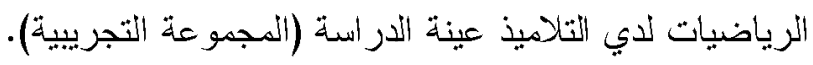


استخدام استراتيجية السقائة التعليمية في تنمية عادات العقل المنتجة لدى طلاب المرحنة الثانوية

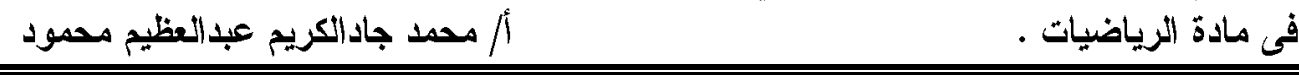

مما سبق ظهرت الحاجة إلى استر اتيجيات حديثة فى تتمية عادات العقل المنتجة، وخاصة

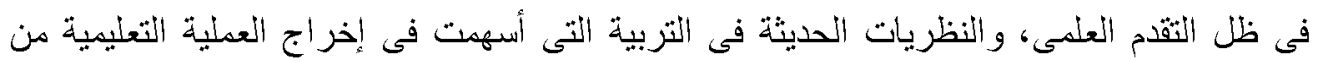

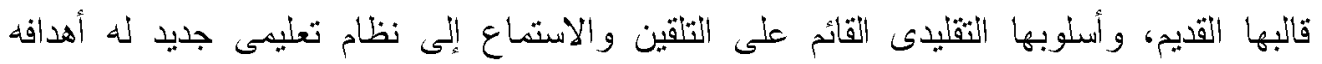

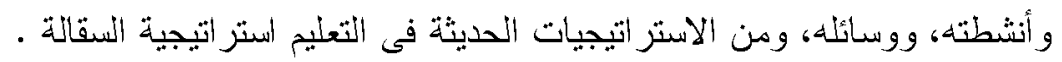

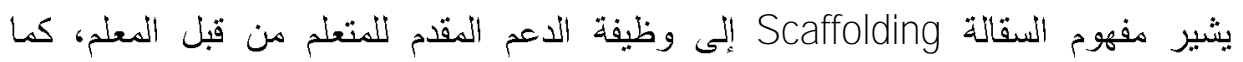
استخدم مفهوم السقالة لوصف عدد كبير من آليات الدعم للمتعلم سواء الدعم البشرى من خلال

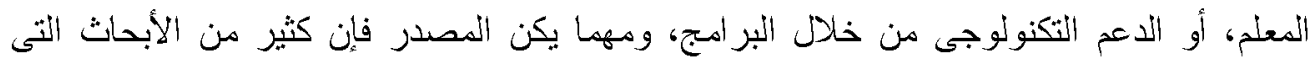

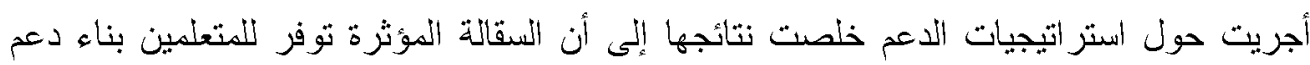

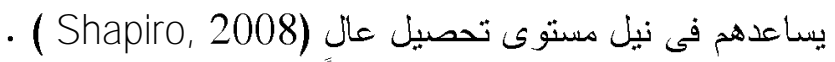
لذا ينبنى عبور الفجوة بين ما يعرفه المتعلم، وما يسعى لمعرفته، وتقليل التعقيد المعرفى

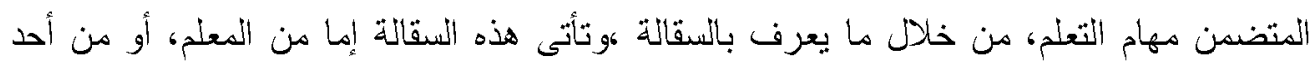

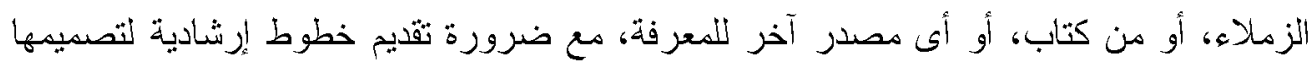

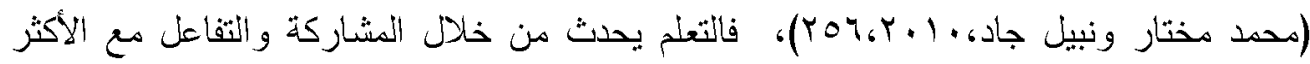

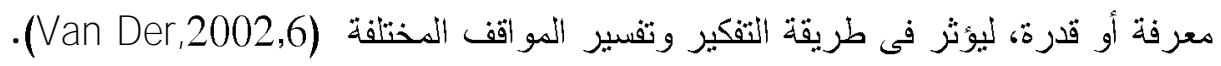
وتعتبر السقالة امتدادًا للنظرية البنائية وإحدى تطبيقاتها، إلا أنها تركز على فئل المتعلم بقصد

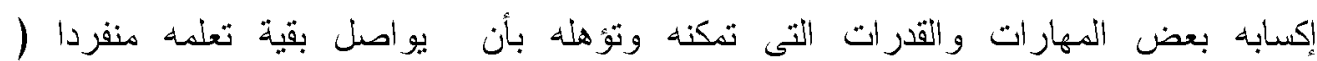
(Shih,2010,85)؛ حيث أن التعليم يحقق أهدافه عندما تقدم للمتعلم تلميحات ومعلومات بلت إرشادية

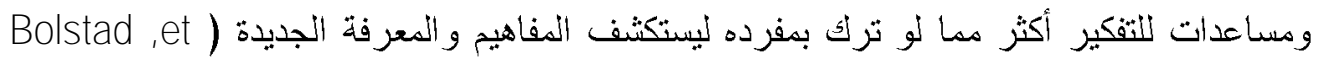
al,2011)، الأمر الذى يجعل السقالة توظف بمثابة الدعم المقدم للمتعلمين، لإثشر اكهم فى الأنثطة

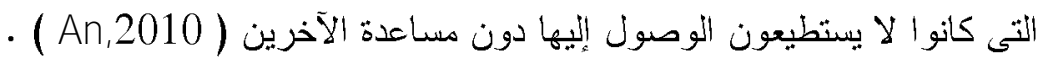

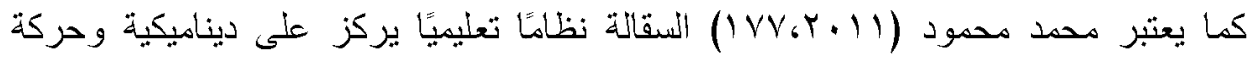

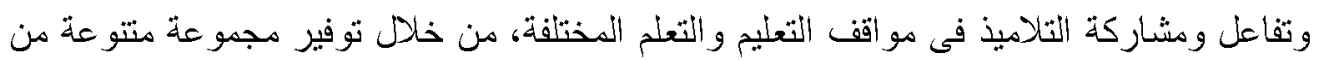

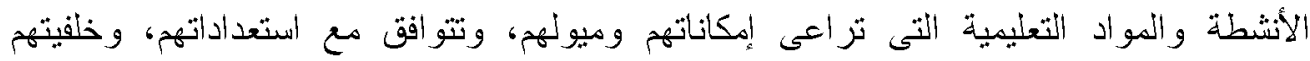

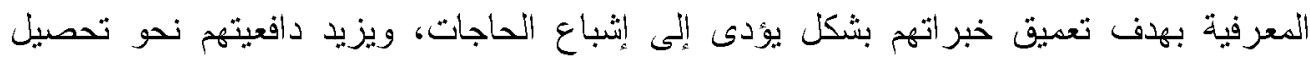
مختلف المعارف مما يتيح لهم فرصدة تتمية مهار اتهم العقلية، وقدر اتهم الخاصنة.

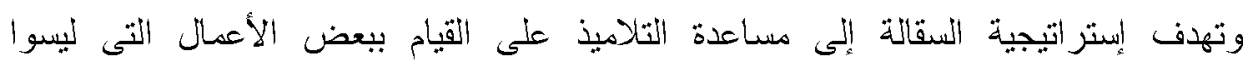

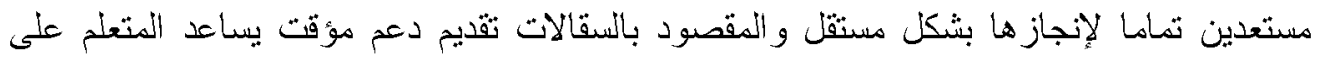

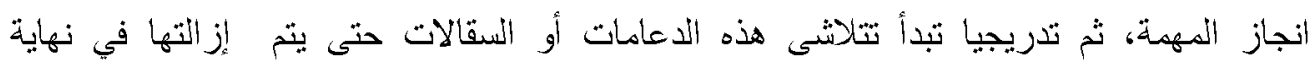
(Van de Pol, et al,2010). المطاف 
استخدام استراتيجية السقالة التعليمية في تنمية عادات العقل المنتجة لدى طلاب المرحلة الثانوية

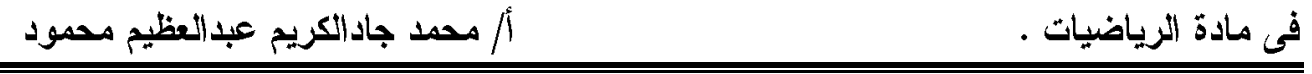

وتوفر استراتيجية السقالة وسيلة فعالة للمتعلمين حيث تنقلهم تدريجيًا بشكل مستقل وفق

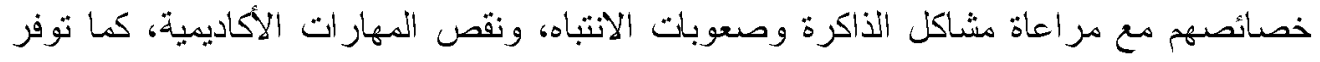

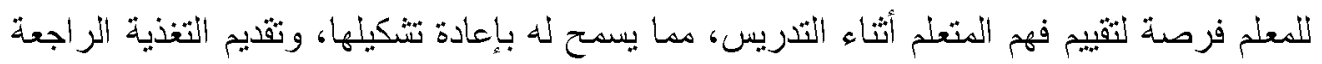
التصحيحية، كل ذلك من دوره أن يقلل من الإحباط (Brower,et al,2018).

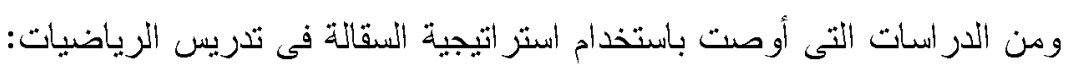

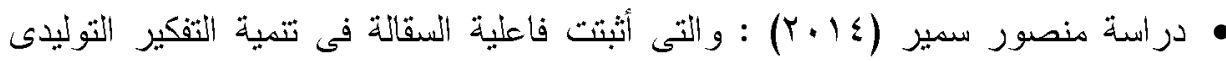
و التحصيل فى وحدة الجبر و الدو ال بالمرحلة المتوسطة.

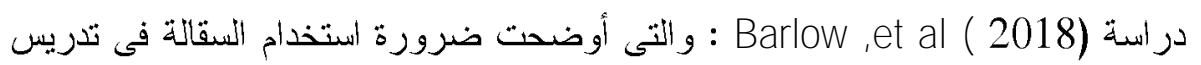

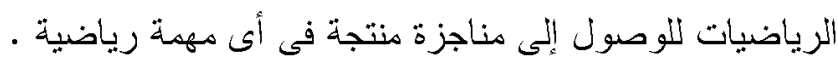

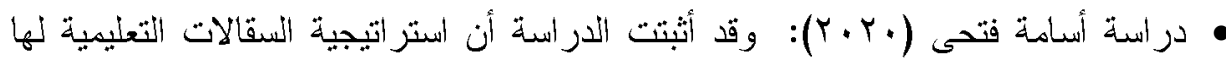

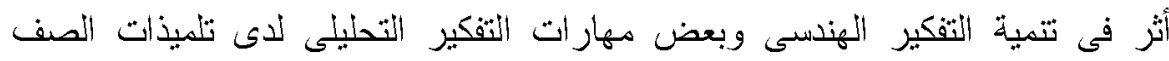

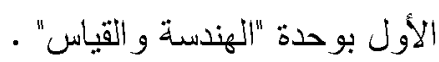

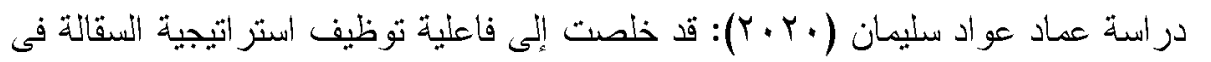
تدريس الرياضيات فى تحسين القوة الرياضية والكفاءة الذانية لدى طلبة المرحلة الثانوية • دراسة فاطمة سعد (Y.Y.Y): وقد أوضحت فاعلية استر اتيجية السقالة فى تتمية مهار ات حل المسألة الزياضية وبقاء أثز التعلم لدى طالبات الصف الثانى متوسط . بناءً على ما تقدم، جاء هذا البحث لبيان اثر استراتيجية السقالة التعليمية في تتمية عادات العقل المنتجة لدى طلاب الصف الأول الثانوى فى الرياضيات.

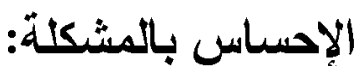

باستثر اء الأدبيات و الدر اسات العابقة التى تتاونت مهار ات التو اصل الرياضى، أكد معظمها

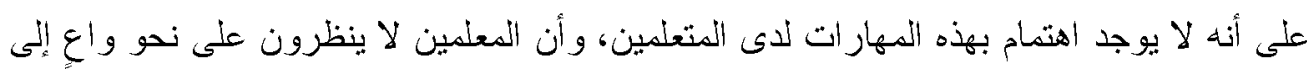

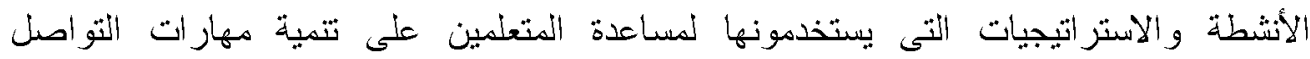
الرياضى، والتدريس بصورته الحالية قد يعوق هذه المهارات ويؤدى إلى ضعفها، ونتيجة لذلك

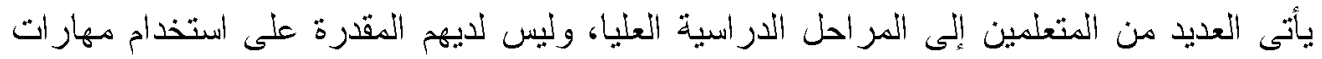
التو اصل الرياضى، بالإضافة إلى ضعف المستوى فى هذه المهار ات.

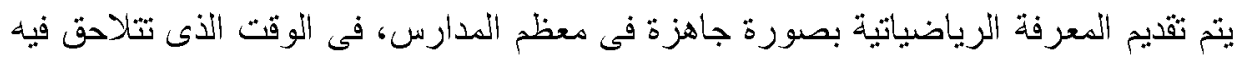

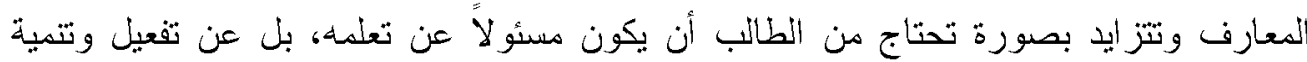

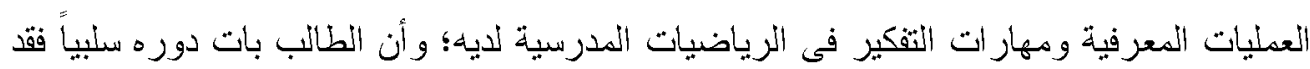


استخدام استراتيجية السقالة التعليمية في تنمية عادات العقل المنتجة لدى طلاب المرحلة الثانوية

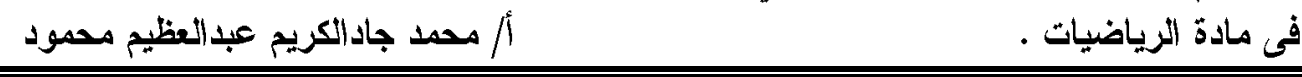

أصبح مجرد منلق للمعرفة الرياضياتية فى وقت أصبح فيه المعلم ملقناً لها؛ وهذا الدور انعكس

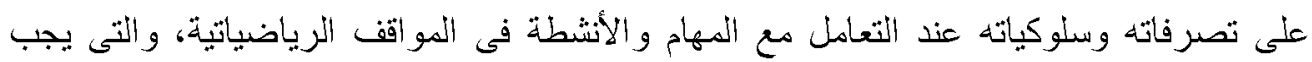

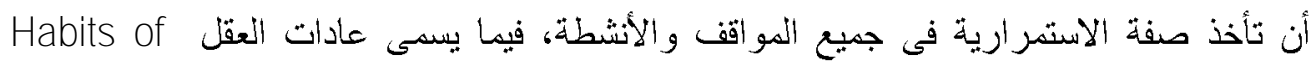
. mind و على الرغم من أهمية عادات العقل المنتجة إلا أن العديد من الدراسات أثشار إلى وجود تدنى بمستوى الطلاب فيها ومن هذه الدر اسات:

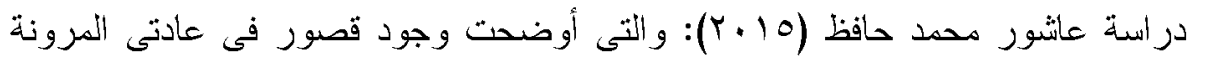

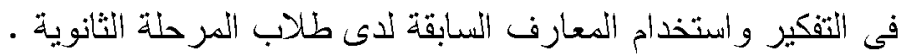

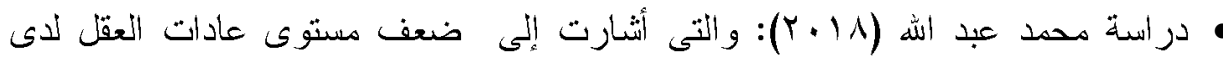

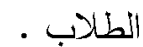
مراسة أحمد علي إبراهيم (1/ (ب): والتى أوضحت ضعف مستوى عادات العقل لدى التنالميذ.

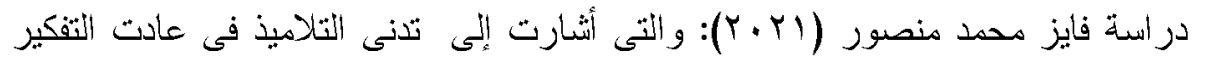

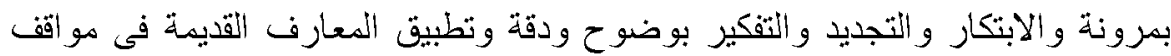
جديدة . ومن خلا الخبرة الميدانية لوحظ تدنى مستوى الطلاب فى عادات العقل المنتجة منمثلة فى

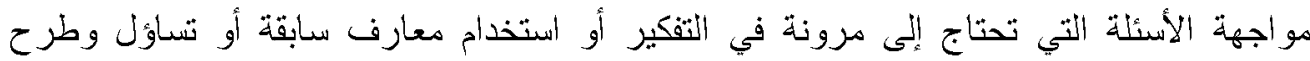

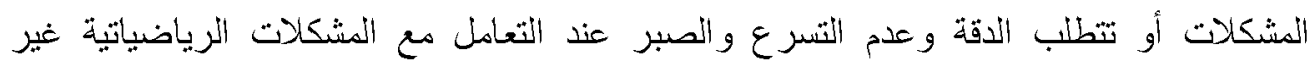

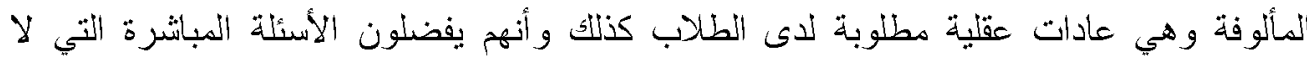
تحتاج إلى مجهود ذهني ووقت أطول. ولاستطلاع المشكلة قام الباحث بإجر اء العديد من المقابلات الثخصية مع عدد ، بمعلم

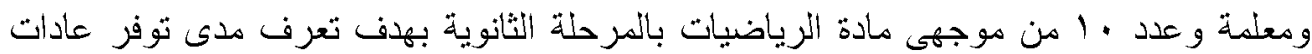

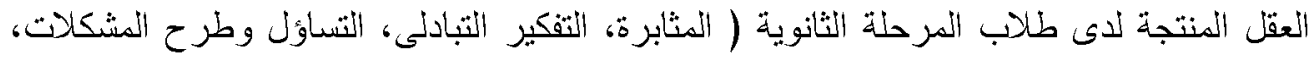

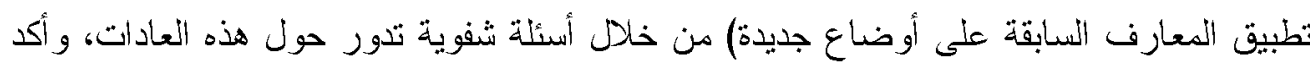

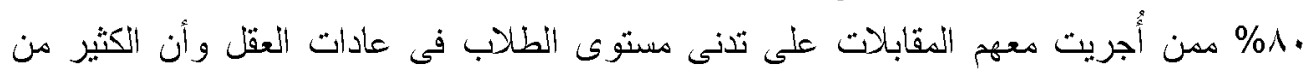
الطلاب يفضلون الأسئلة المباثرة، ومعظمه لا يجيد التفكير فى حل المساثل التى بها ارتباط

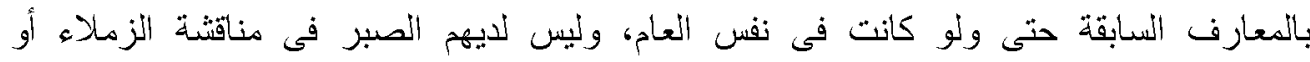
المعلمين فى حول التمارين، و عدم الإقدام على المشكلات الرياضية بصنفة عامة. 
استخدام استراتيجية السقالة التعليمية في تنمية عادات العقل المنتجة لدى طلاب المرحلة الثانوية

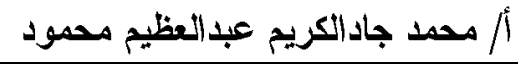

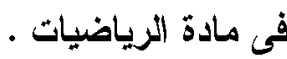

كما تم نطبيق مقياس لعادات العقل مكون من · r مفردة يهدف إلى قياس بعض عادات

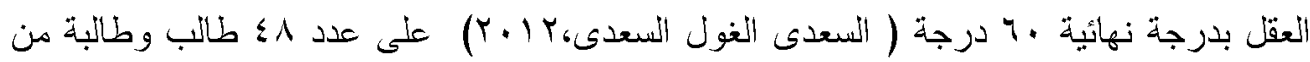

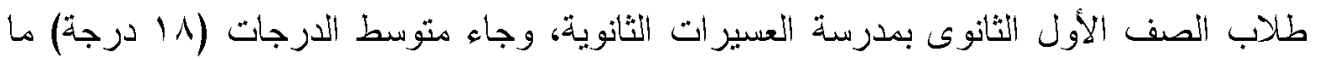

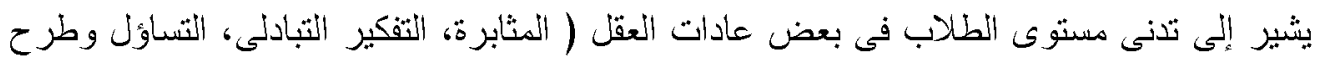

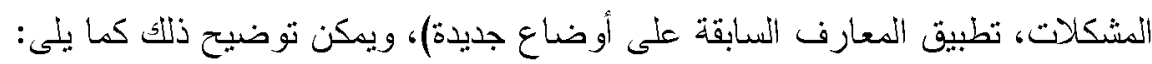
قبول الطلاب للحلول الأولى المباشرة وعدم الاستمرارية فى البحث عن علاقات متباينة داخل النموذج أو الموقف الرياضياتى. نقص القدرة على التو اصل بشكل كبير مع الآخرين والتعاطف و العطف و القبادة الجماعية

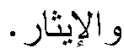

عدم القدرة على حل المشكلات وضعف مهارة طر ح الأسئلة . انعدام الخبرة العلمية حول كيفية الاستفادة من المشكلات التى تم دراستها فى تتفيذ الحل اللشكلات الجديدة.

وفى ضوء ما سبق يتضح مدى الحاجة إلى التعرف على أثنر استر اتيجية السقالة التعليمية في تتمية عادات العقل المنتجة لدى طلاب الصف الأول الثانوى فى الرياضيات . مشكلة البحث : تكمن مشكلة البحث الحالى فى تدنى بعض عادات العقل المنتجة لدى معظم طلاب الصف

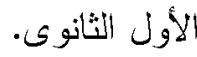

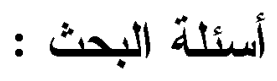
يمكن بلورة مشكلة البحث فى التالى : ما اثر استخدام استر اتيجية السقالة التعليمية في تتمية عادات العقل المنتجة لدى طلاب الصف الأول الثانوى فى مادة الرياضيات ؟ هدف البحث :

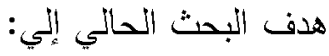
تعرف أثر استخدام استر اتيجية السقالة التعليمية في تتمية عادات العقل المنتجة لــدى طـلاب

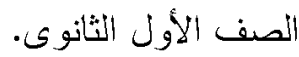


استخدام استر اتيجية السقانة التعليمية في تنمية عادات العقل المنتجة لدى طلاب المرحلة الثانوية

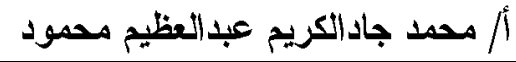

قد يفيد البحث الحالى فيما يلى:

1- تقديم نموذج لتدريس إحدى الوحدات الدراسية لمنهج الرياضيات للصف الأول الثانوى باستخدام إستراتيجية السقالة التعليمية، يمكن لمعلمى وموجهى الرياضيات بالمرحلة الثانوية الثراتي الاستعانة به عند تدريس موضو عات الرياضيات.

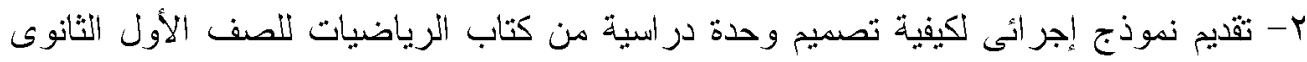

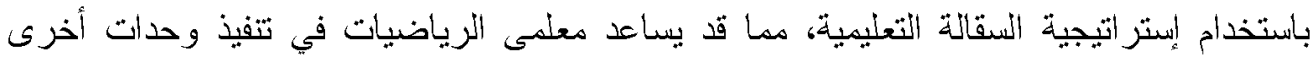
بنفس الطريقة. r- لفت انتباه مطورى مناهج الزياضيات إلي ضرورة الاهنمام بعادات العقل المنتجة لدي المتعلمين عند تصميم الأنثطة المختلفة بالمقرر ات الأراسية.

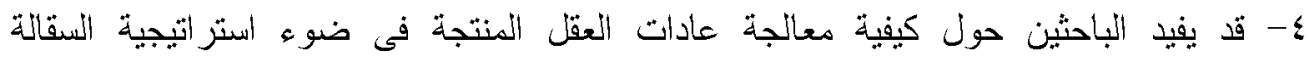

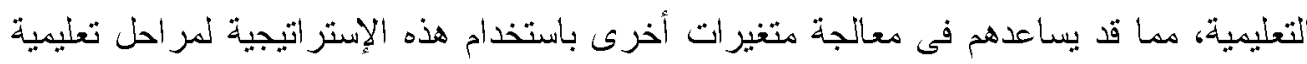

مختلفة.

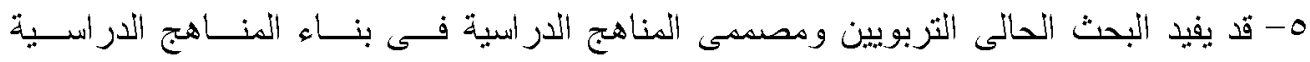

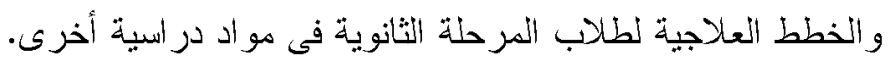

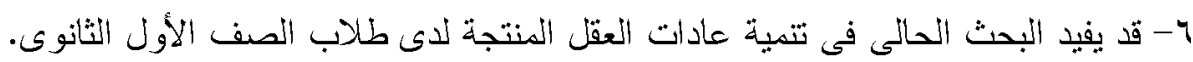

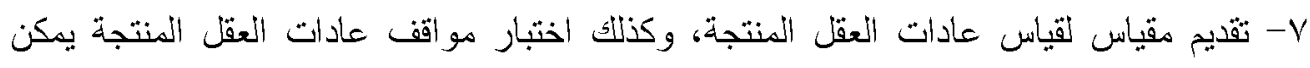
استخدامهما من قبيل الباحثين ومعلمى الرياضيات.

\section{: منهج البحث}

تم في هذا البحث استخدام المنهج شبه التجريبى؛ وذلك عند اختيار مجموعة البحث وتطبيق الأدوات قبلياً و هما: مقياس عادات العقل المنتجة واختبار مو اقف لعادات العقل المنتجة، ثم التدريس

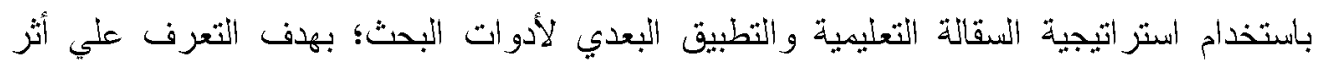

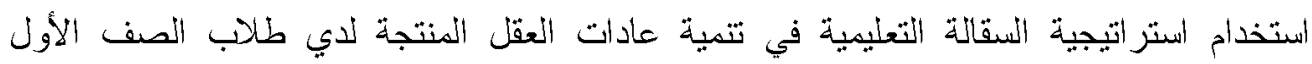
الثانوى.

\section{حدود البحث:}

التزم البحث الحالي بالحدود التالية: - تجربة استخدام استراتيجية السقالة التعليمية لتدريس منهج الرياضيات للصف الأول

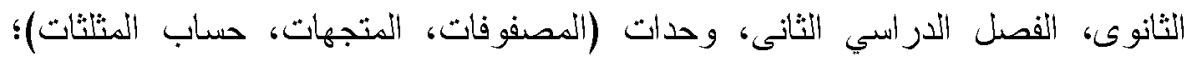


استخدام استر اتيجية السقانة التعليمية في تنمية عادات العقل المنتجة لدى طلاب المرحلة الثانوية

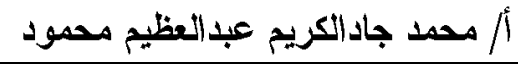

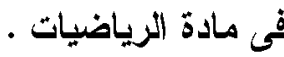

وذلك لثزاء الوحدات بالمادة العلمية وإمكانية صياغتها باستخدام استراتيجية السقالة

التعليمبة.

- طلاب الصف الأول الثانوى بمدرستى الثهيد وسام منصور الثانوية والعسيرات الثانوية

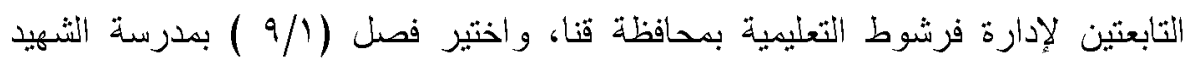

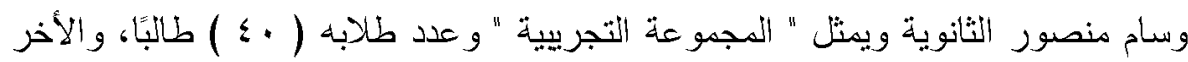

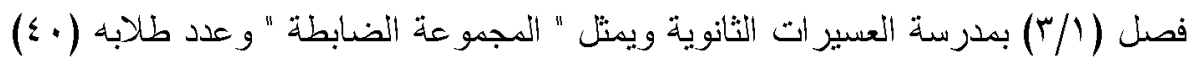
طانبًا.

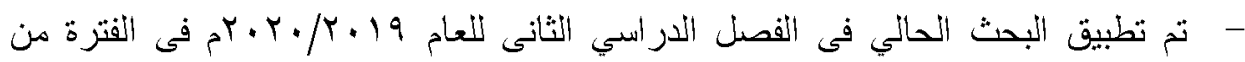

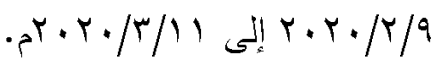

مواد البحث

1- 1 - مائمة عادات العقل المنتجة.

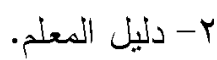

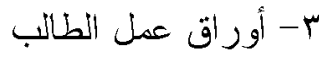
أدوات البحث

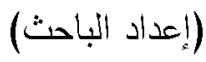

1- 1- مقياس عادات العقل المنتجة. (إعداد الباحث)

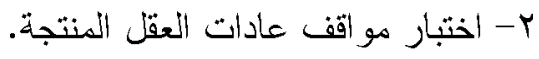
فروض البحث

لإيجاد حلول المشكلة يحاول البحث الحالي تقصى الفروض الآتية:

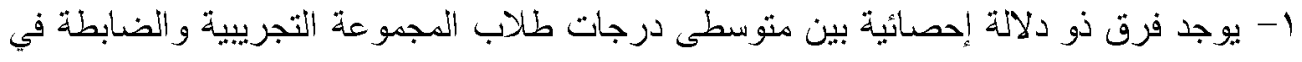

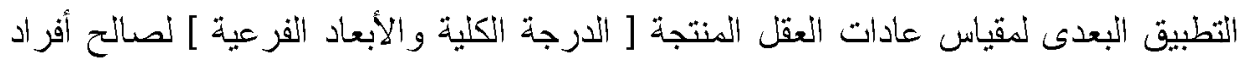
المجمو عة التجرييية. ץ- يوجد فرق ذو دلالة إحصائية بين متوسطى درجات طلاب المجموعة التجريبية و الضدابطة فى

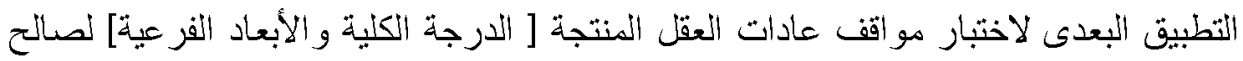
أفر اد المجموعة التجريبية.

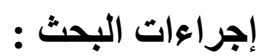
1- لإرساء دعائم الإطار الفلسفى النظرى الذى بنطلق مذه هذا البحث تم:

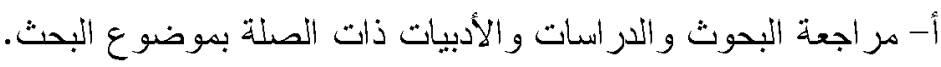

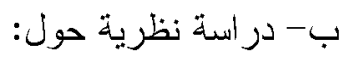
- ماستر اتيجية السقالة التعليمبة.

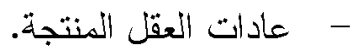


استخدام استراتيجية السقالة التعليمية في تنمية عادات العقل المنتجة لدى طلاب المرحلة الثانوية

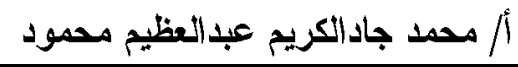

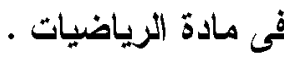

ץ- اختبار وحدات (المصفوفات، المتجهات، حساب المثلثات) من مقرر مادة الرياضيات الفصل الأر اسىى الثانى للصف الأول الثانوى، وتحليل المحتوى العلمى لهات التها. ؛ - إعداد كتيب الطالب فى الوحدات المختارة باستخدام استر اتيجية السقالة التعليمية.

ه- إعداد دليل المعلم لبيتخدم للتندريس للمجمو عة التجريبية.

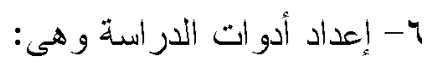
- مقياس عادات العقل المنتجة. - اختبار مو اقف عادات العقل المنتجة.

$$
\begin{aligned}
& \text { V- ضبط وتثقنين أدو ات الدر اسة. } \\
& \text { 1- التصميم التجريبى ويشمل: }
\end{aligned}
$$

أ- اختيار عينة من طلاب الصف الأول الثانوى بإدارة فرشوط التعليمية بمحافظة قنا، وتقسيمهر

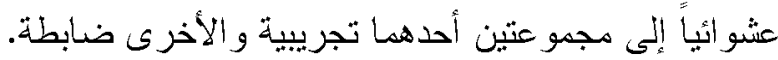
ب- تطبيق أدو ات الدراسة قبل تدريس الوحدة المختارة للتبأكد من تكافؤ المجمو عتين.

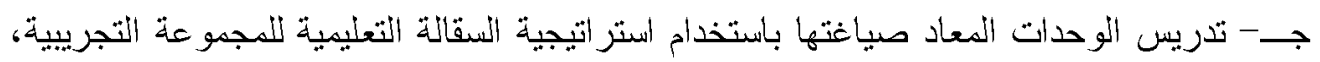
وتدريس نفس الوحدة كما هى بكتاب الوز ارة للمجموعة الضدابطة بالطريقة المتبعة في المدارس.

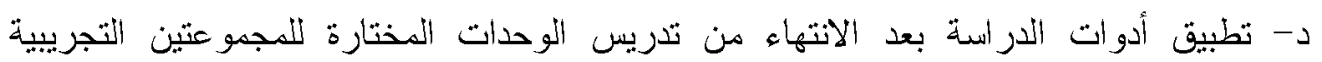
و والضدابطة.

9- معالجة النتائج إحصدائيًا في ضوء التطبيقين القبلى و البعدى لأدو ات الدر اسة. 1 - استخلاص النتائج ومناقتشها وتفسير ها.

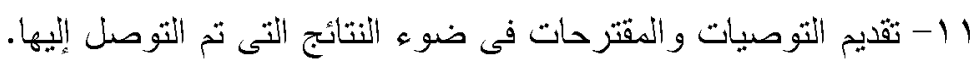
مصطلحات البحث

Educational scaffolding strategy: استر اتيجية السقالة التعليمية البية

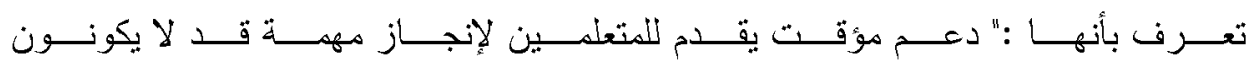

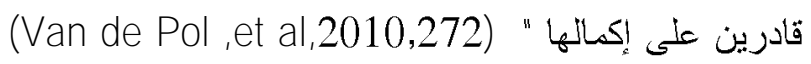
وتُعرف بأنها:"تحقيق أفضل تعلم ممكن لدى المتعلم وخاصدة عن موضوع يدرس لأول مرة،

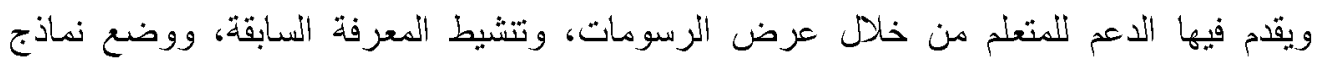

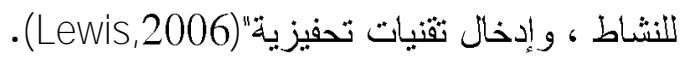

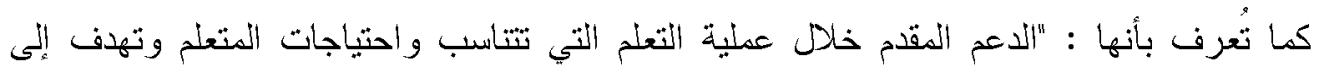

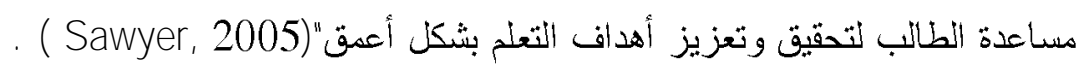


استخدام استراتيجية السقالة التعليمية في تنمية عادات العقل المنتجة لدى طلاب المرحلة الثانوية

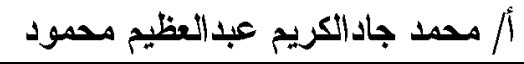

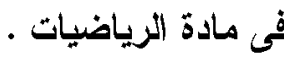

وتعرف إجر ائيًا بأنها : عبارة عن الدعم والمساندة باستخدام أفكار بسيطة أولية والتى يستطيع

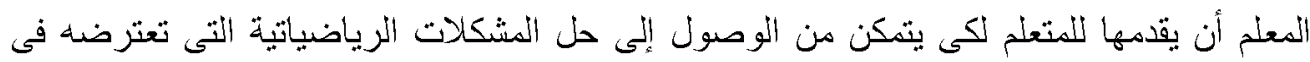
دروسه .

\section{عادات العقل المنتجة Productive Habits of Mind :}

تعرن عادات العقل المنتجة بأنها: "مجموعة المهار ات، و الاتجاهات، و القيم التى تمكن الفرد

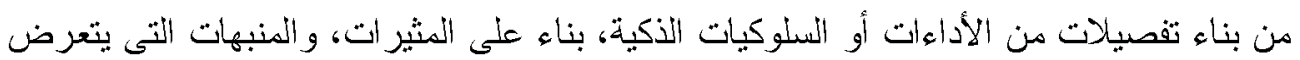

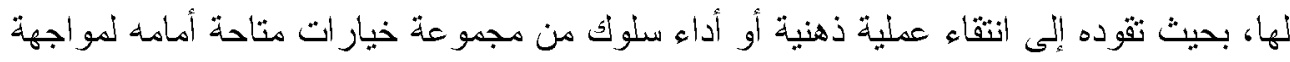

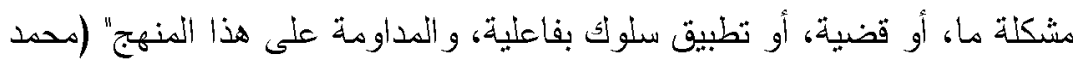

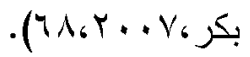

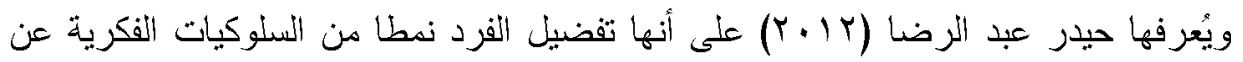

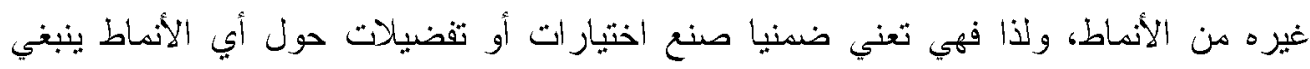

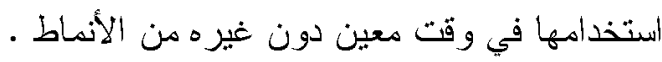

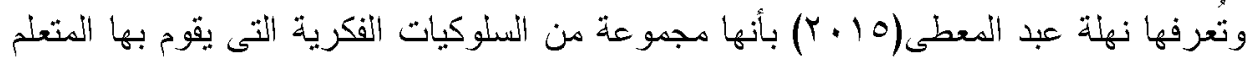

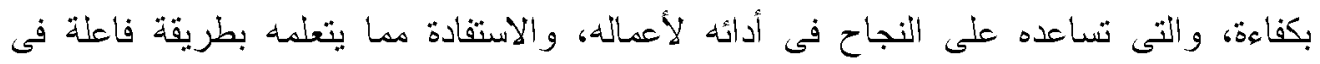
المو اقف الجديدة، وحل ما يقابله من مشكلات في حياته. وتعرف إجر ائياً بأنها : مجموعة السلوكيات الفكرية المرتبطة بكل من من ( المثنـابرة، التفكيــر

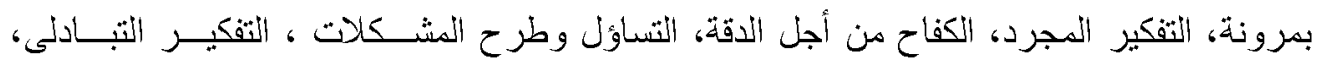

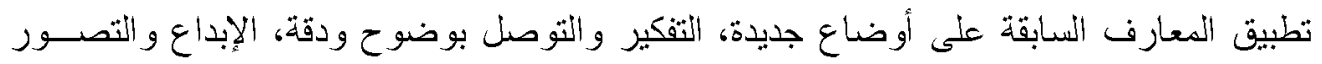

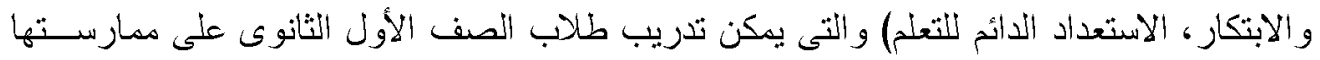

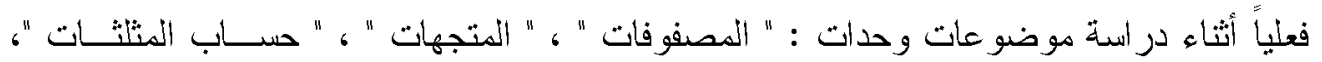

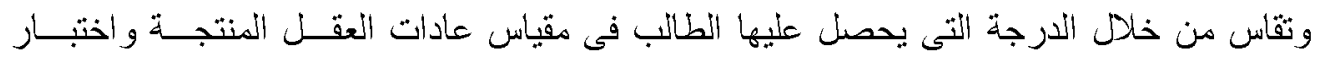

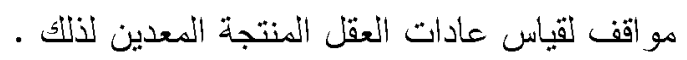

\section{تطبيق البحث:}

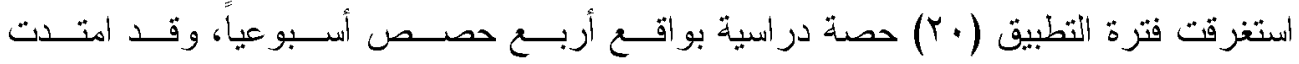

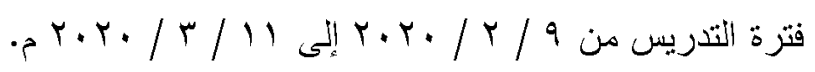
نتائج البحث وتفسير هن

النتائج المتعلقة بأداء الطلاب في مقياس عادات العقل المنتجة في الرياضيات:

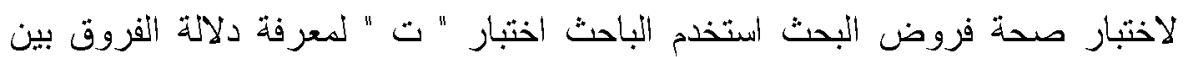

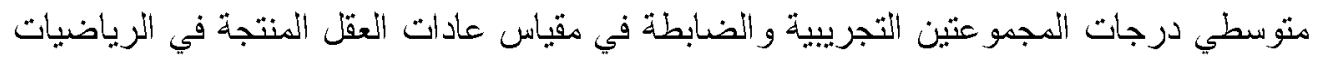


استخدام استر اتيجية السقالة التعليمية في تنمية عادات العقل المنتجة لدى طلاب المرحلة الثانوية

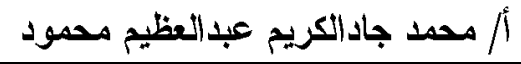

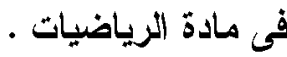

الفرض الأول : لاختبار الفرض الأول الذي ينص علي أنه يوجد فرق ذو دلالة إحصائية بين متوسطى درجات طلاب المجموعة التجريبية والضابطة في التطبيق البعدي لمقياس عادات العقل

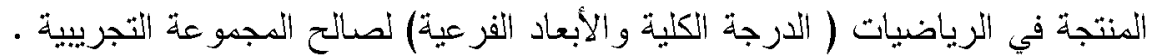

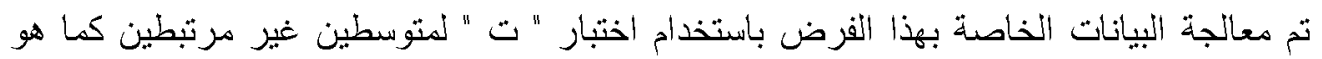

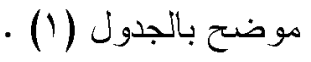

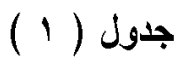

دلالة الفروق بين متوسطات درجات طلاب مجموعتي البحث في التطبيق البعدي لمقياس عادات

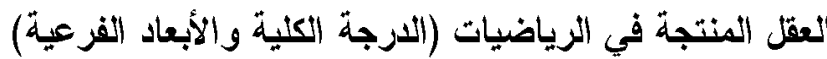

\begin{tabular}{|c|c|c|c|c|c|c|c|c|}
\hline التأثير & $\eta^{2}$ & مستوى الدلالة & "تّة" قيمة & $\varepsilon$ & p & $\dot{ن}$ & المجموعة & الأتغعادات \\
\hline \multirow[t]{2}{*}{ كبيز } & $\cdot . \wedge \uparrow$ & $\because \cdot 1$ & $r \wedge .1$. & $1 . \leqslant \varepsilon$ & $r 1 . \cdot r$ & $\varepsilon$. & التجريبية & المثابرة \\
\hline & & & & $1 .+1$ & $1 \cdot . \leqslant r$ & $\varepsilon$. & الضابطة & \\
\hline \multirow[t]{2}{*}{ كبير } & $\cdot \wedge \varepsilon$ & $\because \cdot 1$ & rq. rV & Y.. 9 & $r \cdot . \leqslant r$ & $\varepsilon$. & التجريبية & التفكير \\
\hline & & & & $1 . \cdot \varepsilon$ & $1 \cdot . v$. & $\varepsilon$. & الضابطة & بمرونة \\
\hline \multirow[t]{2}{*}{ كبير } & 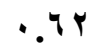 & $\because \cdot 1$ & $Y \leq . \wedge q$ & $r_{.} .0$ & $19 . \wedge r$ & $\varepsilon$. & التجريبية & التفكير \\
\hline & & & & 1.11 & $1 . .0 r$ & $\varepsilon$. & الضابطة & التبادلى \\
\hline \multirow[t]{2}{*}{ كبير } & .04 & $\because \cdot 1$ & Tr.s & $1 . r 9$ & $r . \wedge r$ & $\varepsilon$. & التجريبية & تطبيق المعارف \\
\hline & & & & $1.7 \mathrm{~V}$ & 1.91 & $\varepsilon$. & الضابطة & أوضاعية عديدة \\
\hline \multirow[t]{2}{*}{ كبير } & $\cdot \wedge 0$ & $\because \cdot 1$ & $r \Lambda .19$ & $1.1 \mathrm{~V}$ & $r$ r.OA & $\varepsilon$. & التجريبية & التساؤز \\
\hline & & & & $1 . r \varepsilon$ & $11 . \wedge$. & $\varepsilon$. & الضابطة & المشكلات \\
\hline \multirow[t]{2}{*}{ كبير } & $\cdot \wedge \varepsilon$ & $\because \cdot 1$ & ro.. & $1 . r \Lambda$ & M. Yo & $\varepsilon$. & التجريبية & الاستعداد \\
\hline & & & & 1.11 & 11.9. & $\varepsilon$. & الضابطة & الدائم للتعلم \\
\hline \multirow[t]{2}{*}{ كبير } & .04 & $\because \cdot 1$ & r. & $r . \cdot \Lambda$ & 19.94 & $\varepsilon$. & التجريبية & الكفاح من أجل \\
\hline & & & & $1 . r v$ & 11.2. & $\varepsilon$. & الضابطة & \\
\hline \multirow[t]{2}{*}{ كبير } & $.0 r$ &.$\cdot 1$ & ro.1s & r.. $q$ & $r \cdot . \varepsilon r$ & $\varepsilon$. & التجريبية & التفكير المجرد \\
\hline & & & & 1.10 & $1 . .90$ & $\varepsilon$. & الضابطة & \\
\hline \multirow[t]{2}{*}{ كبير } & $.7 r$ & $\because \cdot 1$ & Yr.OV & r.11 & 19.50 & $\varepsilon$. & التجريبية & الإبداع \\
\hline & & & & 1.19 & $1 . .7$. & $\varepsilon$. & الضابطة & و والابتكار \\
\hline \multirow[t]{2}{*}{ كبير } & $\because \leqslant V$ &.$\cdot 1$ & $r \cdot . t r$ & 1.1 & $r \cdot . \leqslant \Lambda$ & $\varepsilon$. & التجريبية & التفكير \\
\hline & & & & I.VY & 11.74 & $\varepsilon$. & الضابطة & بوضو حو ودقة \\
\hline \multirow[t]{2}{*}{ كبير } &.$\wedge 4$ & $\because \cdot 1$ & Mr.IA & 10.74 & $r .7 .91$ & $\varepsilon$. & التجريبية & الدرجة الكلية \\
\hline & & & & $1 \cdot .71$ & $11 \cdot .9$. & $\varepsilon$. & الضابطة & \\
\hline
\end{tabular}


استخدام استر اتيجية السقانة التعليمية في تنمية عادات العقل المنتجة لدى طلاب المرحلة الثانوية

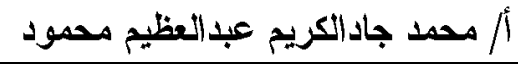

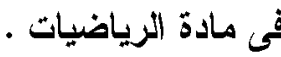

* يشير كل من ( فؤاد عبداللطيف أبو حطب ، آمال أحمد مختار ، 1994، 9بـ ؛ رشدي فام

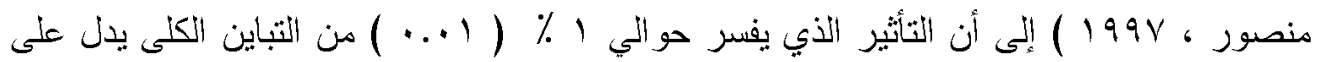

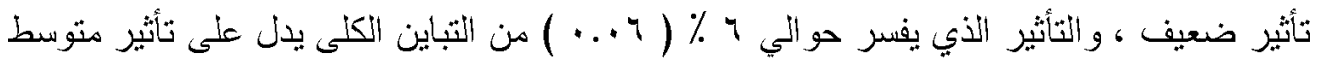

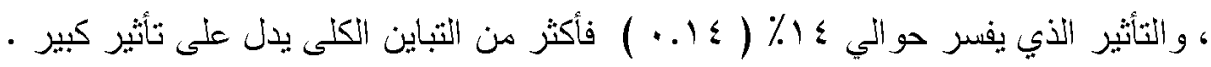

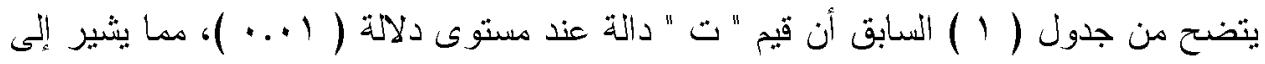
وجود فروق ذات دلالة إحصائية بين متوسطات درجات طلاب المجموعة التجرييية (التى درست

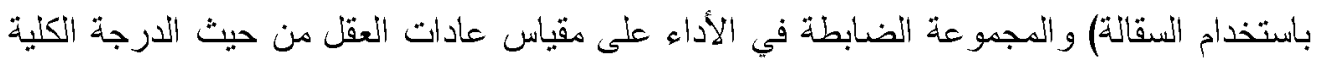

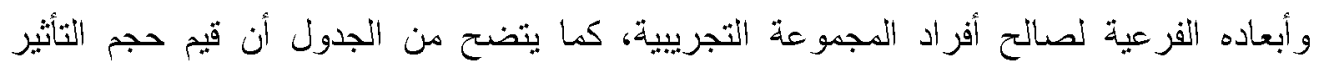

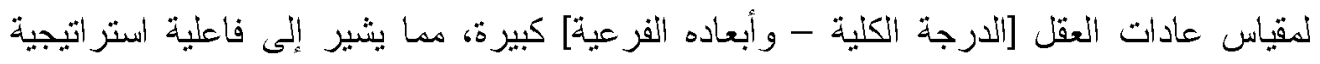

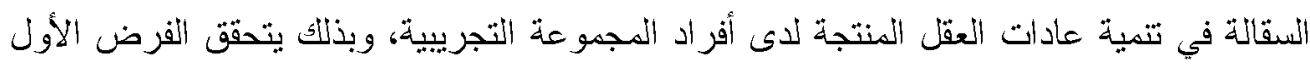

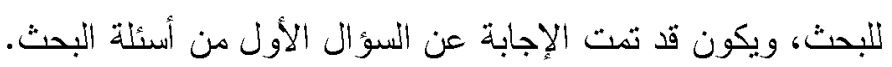

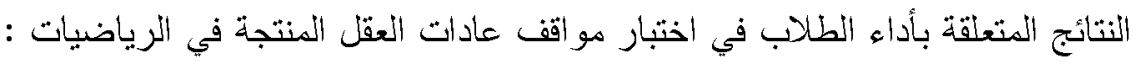
لاختبار صحة فروض البحث استخدم الباحث اختبار " ت " لمعرفة دلالة الفروق بين متوسطات

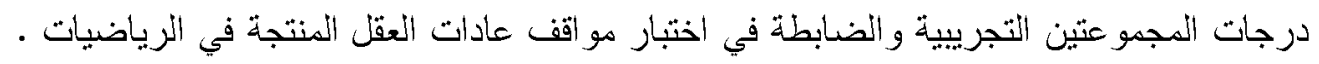

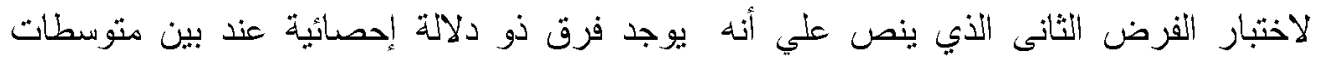

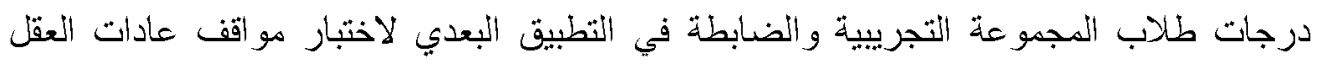

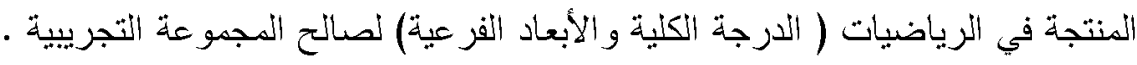

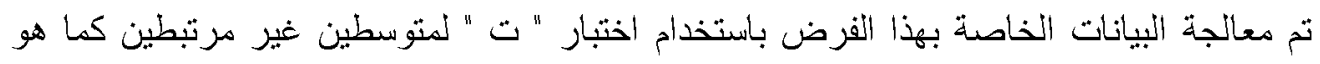
موضح جدول ( أن ).

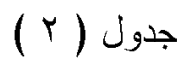

دلالة الفروق بين متوسطات درجات طلاب مجموعتي البحث في التطبيق البعدي لاختبار مو اقف

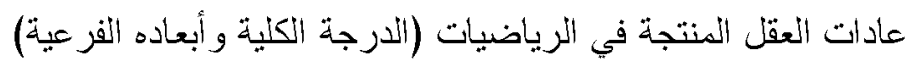

\begin{tabular}{|c|c|c|c|c|c|c|c|c|}
\hline التأثجر & $\eta^{2}$ & مستوي & "تيمة " & $\varepsilon$ & 5 & ن & المجموعة & الأبتغيرات \\
\hline كبيز & .97 & $\because 1$ & Ir.qV & $1 . \cdots$ & $\begin{array}{l}0.10 \\
1.50\end{array}$ & $\varepsilon$. & الضنريبية & المثابرة \\
\hline كبير &.$\vee V 7$ & $\because+1$ & $1 . . r 1$ & $\begin{array}{l}1.59 \\
1.51\end{array}$ & $\begin{array}{l}\varepsilon .50 \\
1.40\end{array}$ & $\varepsilon$. & الضجريبية & التفكير بمرونة \\
\hline كبير &.$\wedge 0$ & $\because 1$ & 1.90 & $\begin{array}{l}1.11 \\
1.25\end{array}$ & & $\varepsilon$. & الضجريبية & التفكير التبادلى \\
\hline كبير & r & $\because 1$ & Ir.. & $\begin{array}{l}1.19 \\
1.19\end{array}$ & $\begin{array}{l}8.10 \\
1.90\end{array}$ & $\varepsilon$. & الضجابطة التية & تلطبيث \\
\hline
\end{tabular}


استخدام استراتيجية السقالة التعليمية في تنمية عادات العقل المنتجة لدى طلاب المرحلة الثانوية

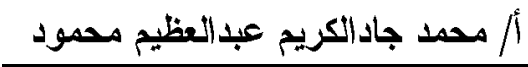

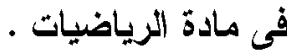

\begin{tabular}{|c|c|c|c|c|c|c|c|c|}
\hline التأثير & $\eta^{2}$ & مستوى & "تيمة" & $\varepsilon$ & 5 & $\dot{ن}$ & المجموعة & الأبتغيرات \\
\hline كبيز & $.0 r$ & $\because+1$ & 0.91 & $\begin{array}{l}1.95 \\
1.11\end{array}$ & r.ro & $\varepsilon$. & الضابطيبية & أوضاع جديدة \\
\hline كبير & .00 & $\because \cdot 1$ & $r . \wedge \varepsilon$ & $\begin{array}{l}1.9 \leq \\
1.5 \leq\end{array}$ & $\begin{array}{l}r .40 \\
1.90\end{array}$ & $\varepsilon$. & الضابطريبة & الاستعداد الدائم \\
\hline كبير & $.0 r$ & $\because+1$ & $0 . \wedge \wedge$ & $\begin{array}{l}r .1 \\
1 . r \leq\end{array}$ & $\begin{array}{l}r .0 . \\
1 . r .\end{array}$ & $\varepsilon$. & الضابطريبة & الكفاح من أجل \\
\hline كبيز & $\because \leqslant V$ & $\because+1$ & $\varepsilon .9 \wedge$ & $\begin{array}{l}r .0 v \\
1.01\end{array}$ & $\begin{array}{l}1.70 \\
1.7 .\end{array}$ & $\varepsilon$. & الضابطريبة & التفكير المجرد \\
\hline كبير & $\cdot \wedge \vee$ & $\because+1$ & $9 . r$. & $\begin{array}{l}1.59 \\
1.59\end{array}$ & $\begin{array}{l}\varepsilon .0 . \\
1.7 .\end{array}$ & $\varepsilon$. & الضابطريبية & والإبصور \\
\hline كبير & .70 & $\because 1$ & $V . \& 7$ & $\begin{array}{l}r .1 r \\
.99\end{array}$ & $\begin{array}{l}r .00 \\
\ddots v .\end{array}$ & $\varepsilon$. & الضجريبية & والابتكار \\
\hline كبير & $\because \wedge 9$ & $\because+1$ & $1 \leq .99$ & $\begin{array}{l}\vee . \vee 0 \\
\wedge . \wedge 0\end{array}$ & $\begin{array}{l}\leqslant 1.40 \\
10.00\end{array}$ & $\varepsilon$. & الضجريبية & \\
\hline
\end{tabular}

* يشير كل من ( فؤاد عبداللطيف أبو حطب ، آمال أحمد مختار ، ب99 19 وبـ؛

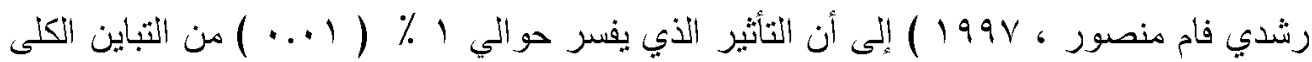
يدل على تأثير ضعيف ، والتأثثر الذي يفسر حوالي ب ٪ ( ؟ . . . ) من التباين الكلى يدل على

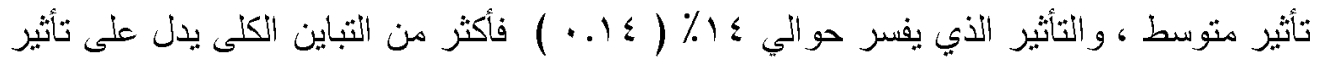
- كبير

يتضح هن جدول (Y) أن قيم " ت " دالة عند مستوى دلالة (1 (.+) ، مما يثير إلى وجود فروق ذات دلالة إحصائية بين منوسطات درجات طلاب المجموعة التجريبية ( التي تعرضت للتجربة ) و المجمو عة الضابطة ( التي لم تثعرض للتجربة ) في اختبار مواقف عادات العقل المنتجة في الرياضيات من حيث الدرجة الكلية وأبعاده الفرعية لصالح أفراد المجموعة التجريبية، كما يتضح من الجدول أن قيم حجم التأثير لاختبار مواقف عادات العقل المنتجة في الترياضيات [الدرجة الكلية - و أبعاده الفرعية] كبيرة، مما يشير إلى فاعلية استر اتيجية السقالة في تتمية عادات العقل المنتجة لدى أفراد المجموعة التجريبية، وبذلك يكون قد تمت الإجابة عن إن التساؤل الثانى من أسئلة البحث وكذا التأكد من صحة الفرض الثانى من فروض البحث.

\section{مناقشة النتائجج وتفسيرها :}

بناءة على النتائج التى تم التوصل إليها من خلال تدريس وحدات (المصفوفات، والمتجهات، وحساب المثلثات) باستخدام استر اتيجية السقالة، و التطبيق القبلى و البعدى لمقياس عادات العقل وحل ولن 
استخدام استراتيجية السقالة التعليمية في تنمية عادات العقل المنتجة لدى طلاب المرحلة الثانوية

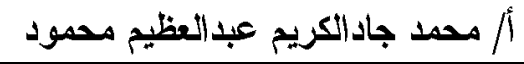

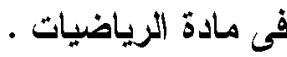

المنتجة واختبار مواقف عادات العقل المنتجة فى الرياضيات، بهذف قياس أستخدام استراتيجية السقالة فى تتمية عادات العقل المنتجة فى الرياضيات لدى طلاب الصف الأول الثانوى . يمكن تحليل هذه النتائج وتفسير ها على النحو التالى :

يتضح من العرض السابق لنتائج البحث لمقياس عادات العقل المنتجة في الرياضيات ما يلى :

ارتفاع ملحوظ في مستوب أداء طلاب المجموعة التجريبية علي أداء طلاب المجموعة

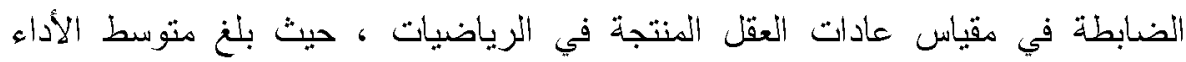

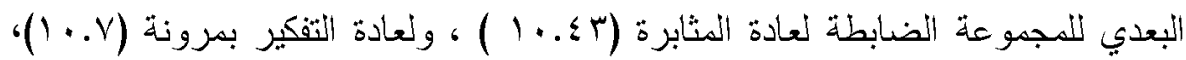

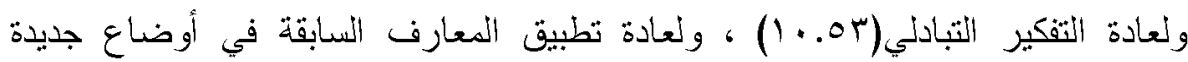

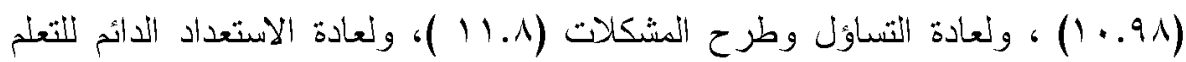

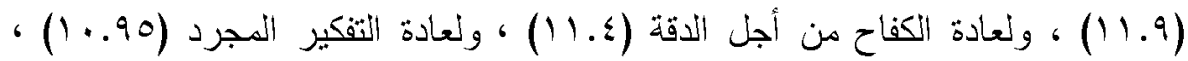

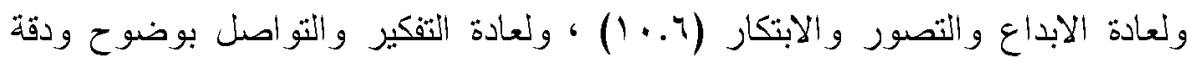

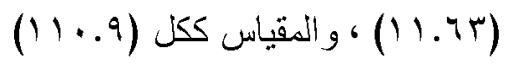

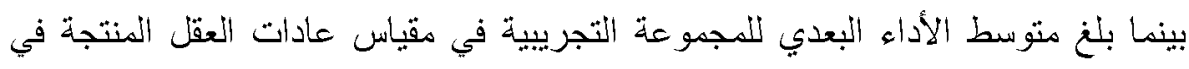

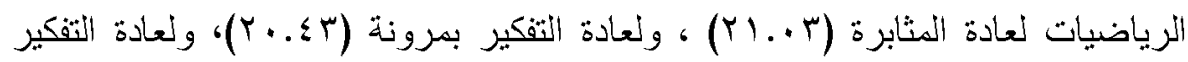

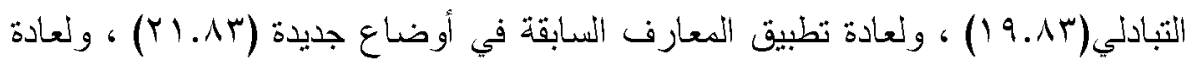

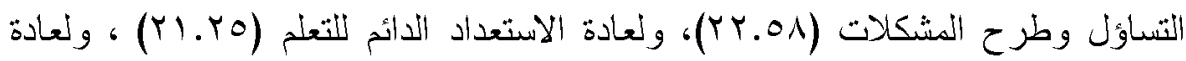

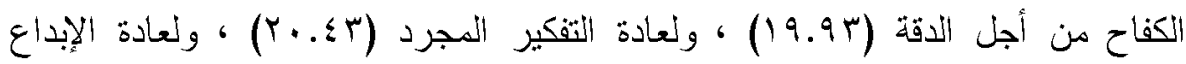

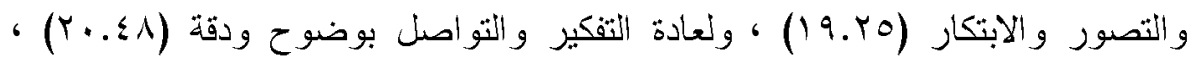

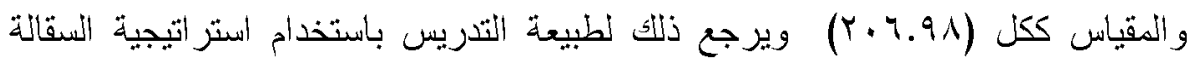

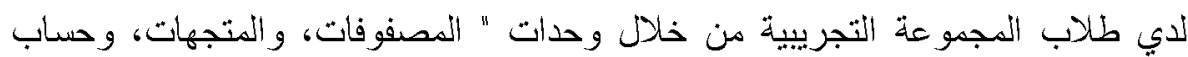

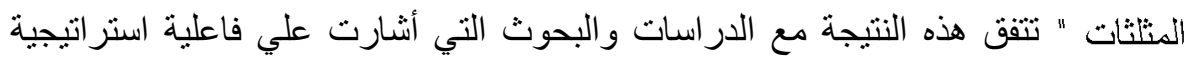

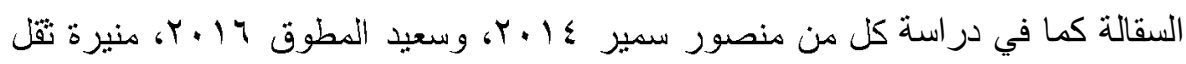

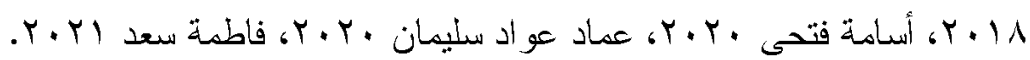

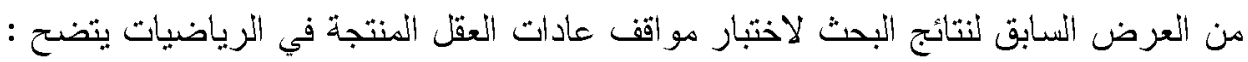
ارتفاع ملحوظ في مستوي أداء طلاب المجموعة التجريبية علي أداء طلاب المجموعة

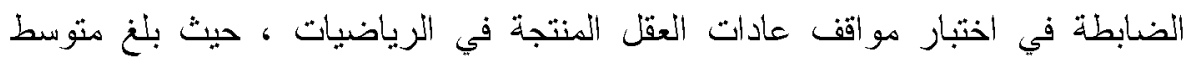

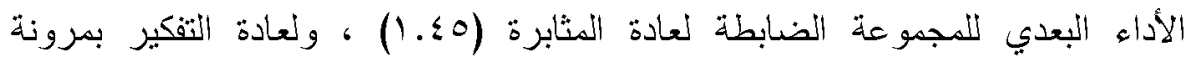


استخدام استر اتيجية السقانة التعليمية في تنمية عادات العقل المنتجة لدى طلاب المرحلة الثانوية

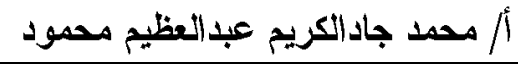

في مادة الرياضيات .

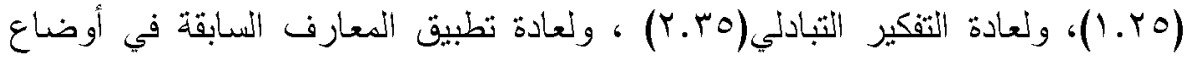

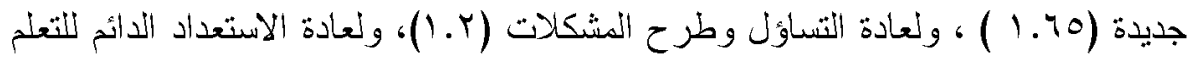

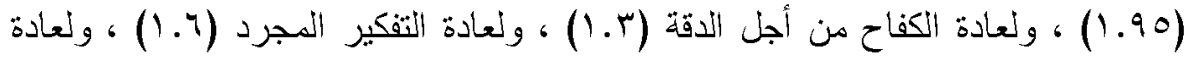

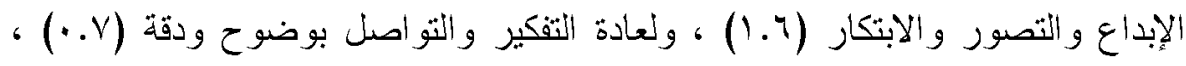
و الكقياس ككل (10.0 (10) .

بينما بلغ متوسط الأداء البعدي للمجموعة التجريبية في اختبار مواقف التف عادات العقل

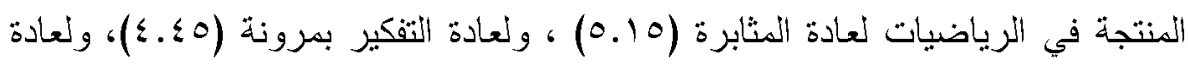

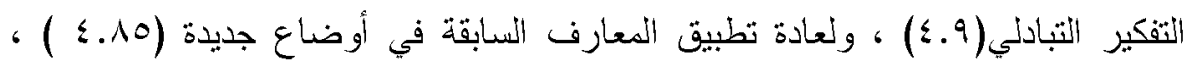

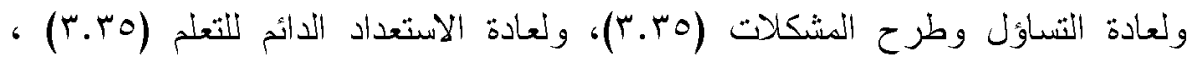

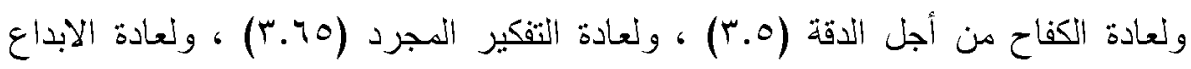

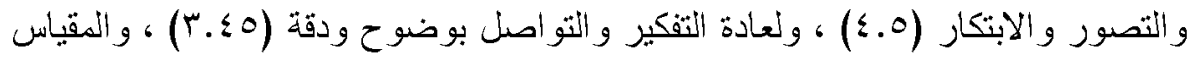

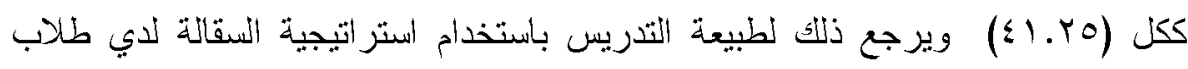
المجموعة التجريبية من خلال وحدات (المصفوفات، والمتجهات، وحساب المثلثات)

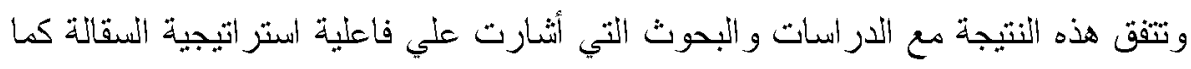

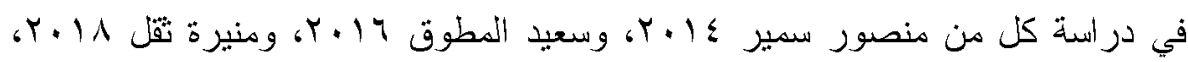

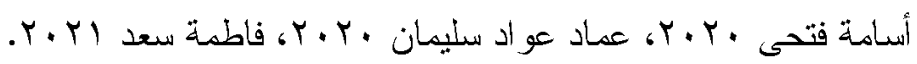

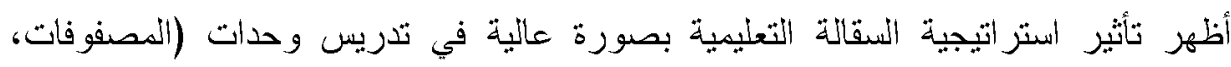

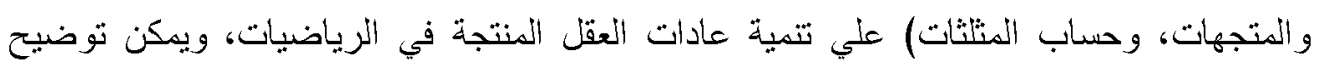
ذلك كما يلي :

- تقديم المعارف و المفاهيم الجديدة في ضوء الخبرات النسابقة للطلاب من حيث ربط ما

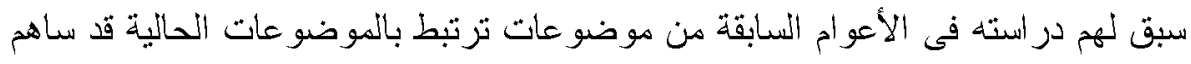

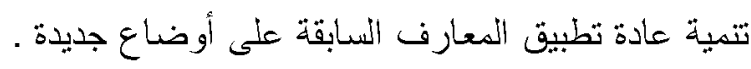

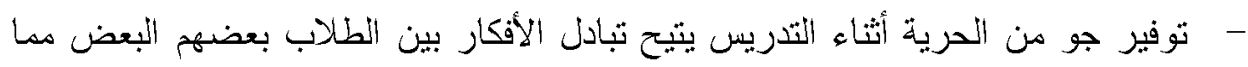

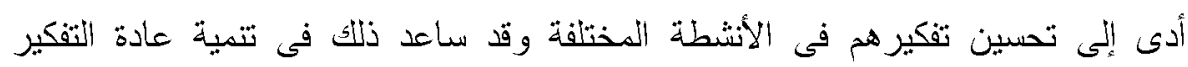
المجرد .

توفير أسئلة متنوعة تثير العادات العقلية وترك مساحة كبيرة لطرح الأسئلة من الطلاب

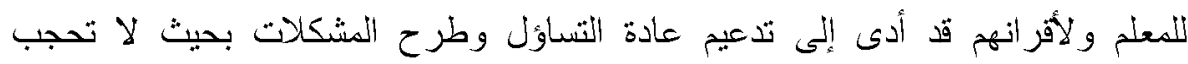

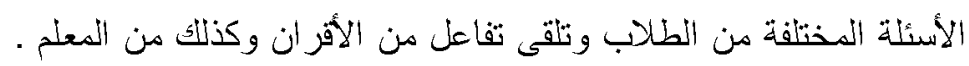


استخدام استز اتيجية السقالة التعليمية في تنمية عادات العقل المنتجة لدى طلاب المرحلة الثانوية

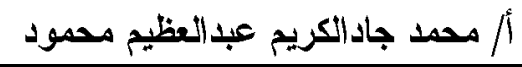

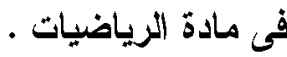

توفير جو من تألف المجموعات لتبادل الأفكار الرياضياتية عمل على زيادة طاقة الطلاب للتتلم مما ساعد فى تتمية عادة الاستعداد الأئم للتعلم . - توفير أسئلة تثير الحماسة والتحدي جعل جميع الطلاب فى حالة متميزة من المثابرة

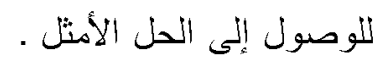
- توفير أمثلة وأنثطة تصقل الطلاب بمعلومات جديدة وتطور من أدائهم بحيث يكون

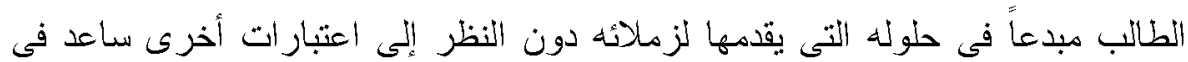

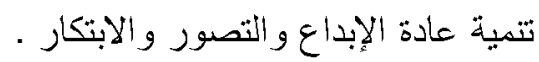

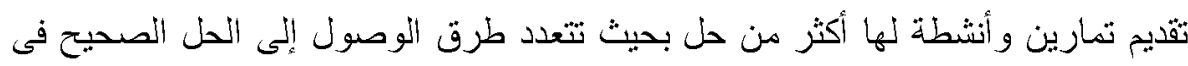

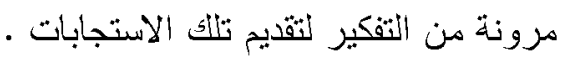
- إثارة أذهان الطلاب بأنشطة غير تقليدية لتثير أفكارهم بشكل غير تقليدي قد أدى دور

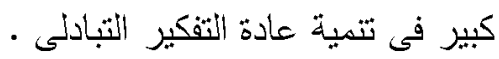
توفير وقت مناسب للتفكير في الأنشطة أسهر بشكل واضئ فئح فى تتمية عادة الكفاح من أجل

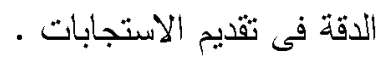
- تقديم أنشطة تقويمية تتابعية أثناء الثرح للتحقق من فهم الطلاب ساعد كثير أ فى جعل

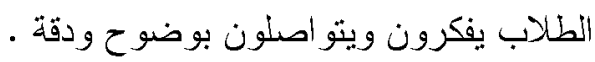
توصيات البحث: في ضوء ما أسفرت عند النتائج النسابقة يوصي البحث الحالي بما يلي :

توجيه نظر معلمي الرياضيات إلي استر اتيجية السقالة التعليمية وكيفية الاستفادة منها في

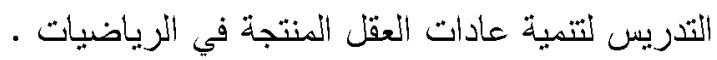

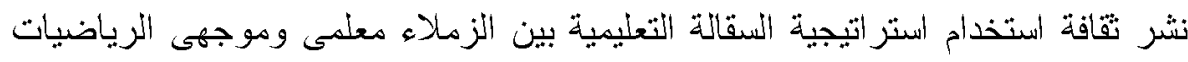

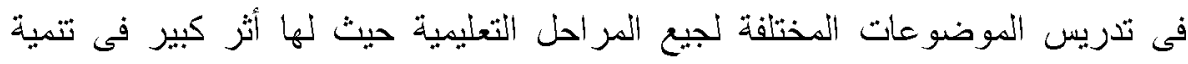

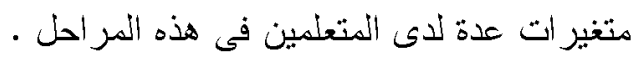

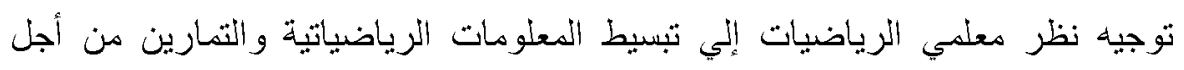
تيسير الفهم بطرق مختلفة وتسهيل استيعاب الطلاب للمادة العلمية . توجيه نظر معلمي الرياضيات إلي توفير جو من حرية التعبير بعيداً عن التهديد و الارتبالك و الاحباط. توجيه نظر معلمي الرياضيات إلي إعطاء أمثلة مثتوعة تزيد من قدرات الطلاب العقلية في البحث و الاكتئناف و المنافسة وتتمية عاداتهم العقلية . 
استخدام استز اتيجية السقالة التعليمية في تنمية عادات العقل المنتجة لدى طلاب المرحلة الثانوية أ/ أ/ محمد جاد الكريم عبدالعظيم محمود

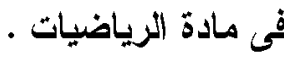

توجيه نظر معلمي الرياضيات إلي ضرورة إعطاء فرص مناسبة للطلاب للتفكير في التمارين الرياضياتية من زوايا متعددة لتتمية عادات العقل المنتجة .

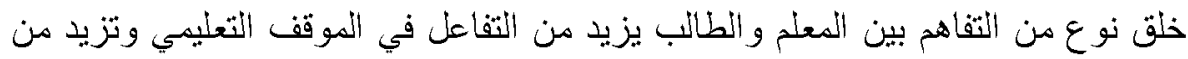

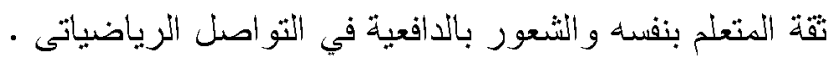

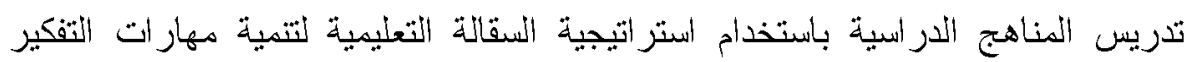

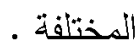

تدريب المعلمين حول استخدام أسئلة تثير تفكيرهم وتنمي عاداتهم العقلية أثثاء التثريس . ضرورة تعزيز مناهج الرياضيات بدليل المعلم الذي يتتاون الطرق والوسائل التعليمية

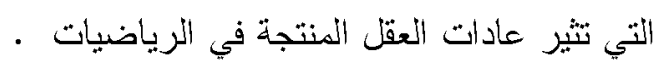
تدريب المعلمين علي استخدام الأسئلة التي تتمي عادات العيات العقل لاي الطلاب وتزيد من

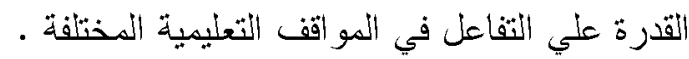
نثر تقافة تتمية عادات العقل المنتجة بين معلمى وموجهى مادة الرياضيات وكذلك

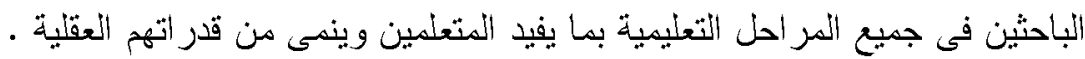

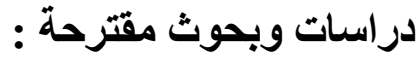
في ضوء نتائج البحث الحالي يمكن اقتر اح المزيد من الدمر اسات و البحوث كما يلي :

إجراء العديد من الدراسات حول استخدام استر اتيجية السقالة التعليمية في تتمية متغيرات

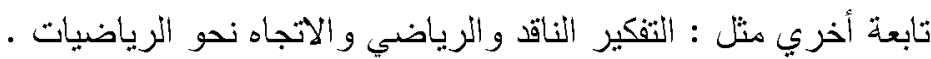

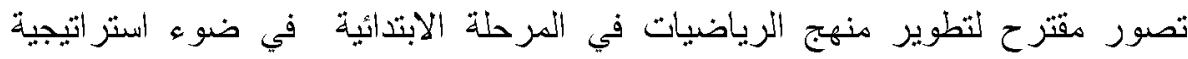

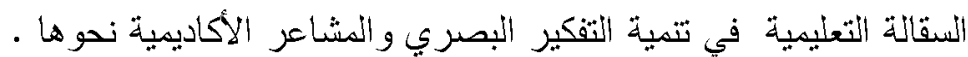

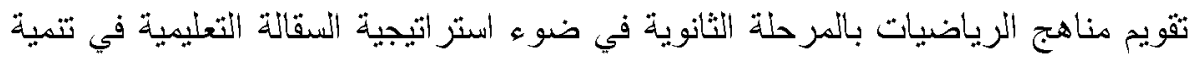

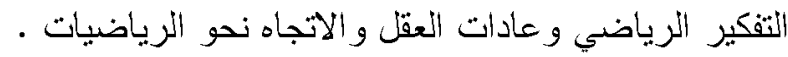

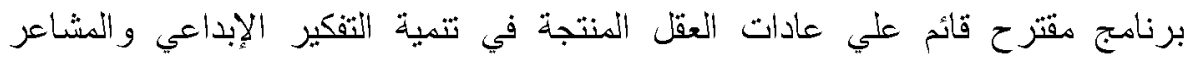
الأكاديمية لاي طلاب المرحة الثانوية . إجر اء دراسة حول أثز استخدام التعلم القائم علي عادات العقل المنتجة في تتمبة دهار التهات

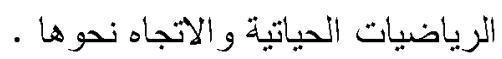
فاعلية وحدة مقترحة فى مادة الرياضيات قائية على استر اتتيجية الليقالة التعليمية فى تتمية مهار ات ما ور اء المعرفة و أبعاد التعلم العميق لدى طلاب المرحلة الثنانوية. 
استخدام استراتيجية السقالة التعليمية في تنمية عادات العقل المنتجة لدى طلاب المرحلة الثانوية

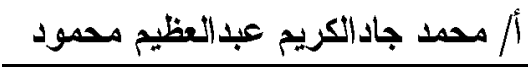

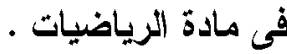

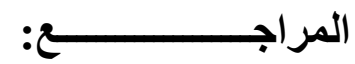

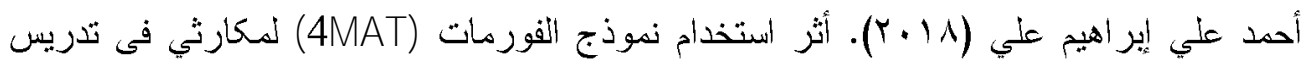
الرياضيات على تتميــة بعض مهار ات التفكير الرياضى وعــادات

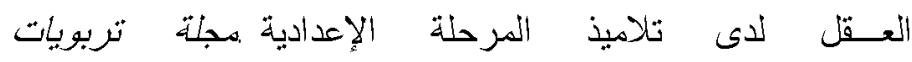

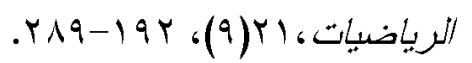

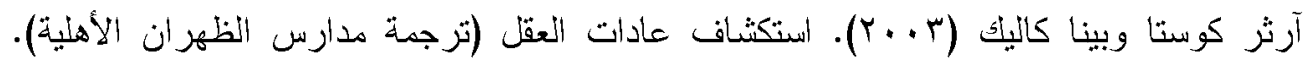

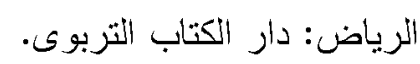

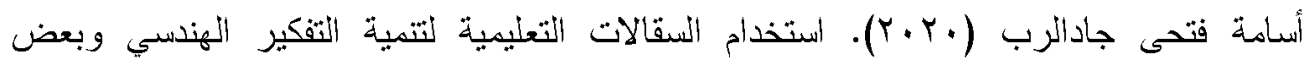

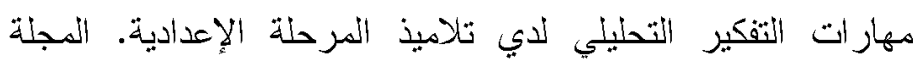

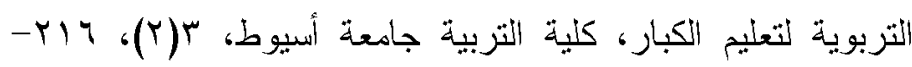

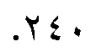

إيمان سمير حمدى (r (ب). فاعلية استخدام نموذج أبعاد التعلم لمارزانو فى تتمية التحصبل

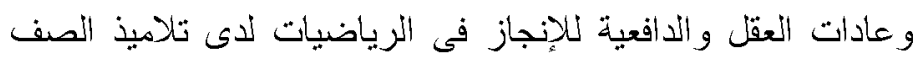

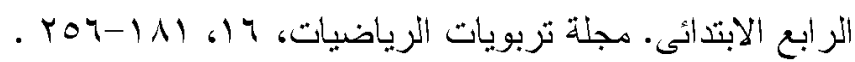

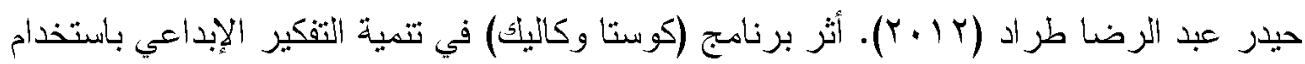

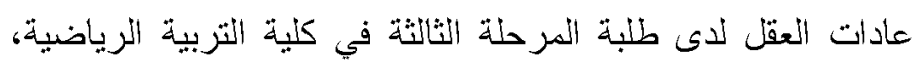

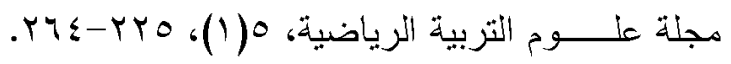

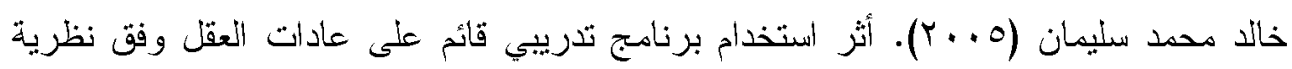

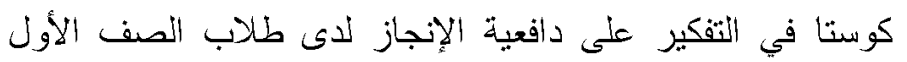

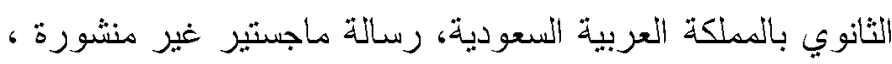
جامعة البلقاء النطبيقية، الأردن.

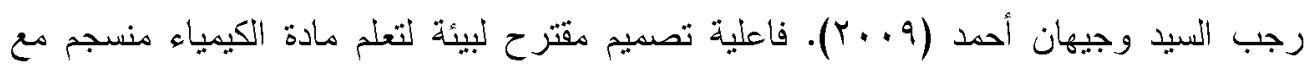

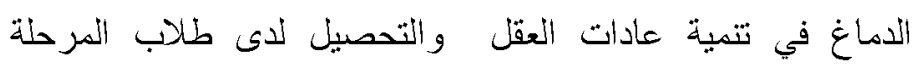

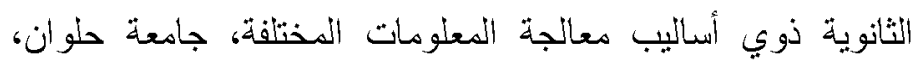

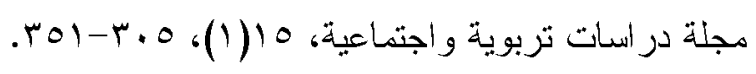

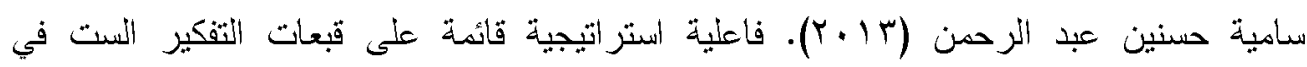

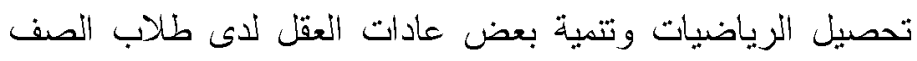

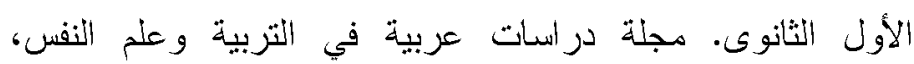

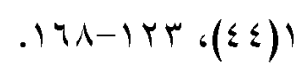


استخدام استراتيجية السقالة التعليمية في تنمية عادات العقل المنتجة لدى طلاب المرحلة الثانوية

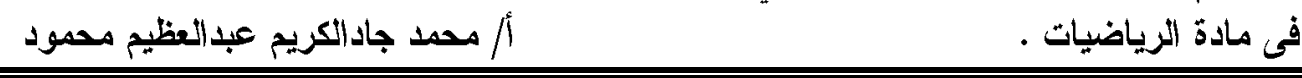

السعدى الغول السعدى (Y ( ب). فاعلية استراتيجية الخرائط الذهنية فى تتمية التفكير التخيلى وبعض عادات العقل لدى تلاميذ المرحة الإعدادية. ورقة مقدمة إلىى

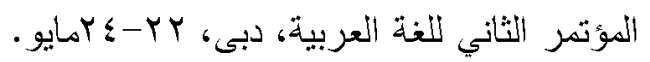

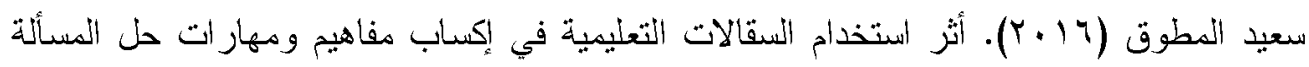

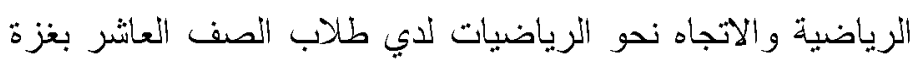

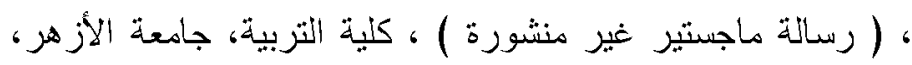
غزة، فلسطين.

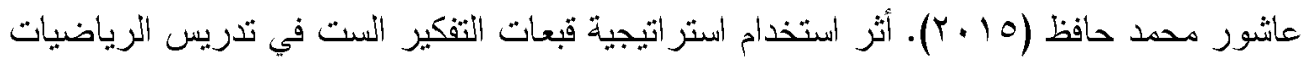

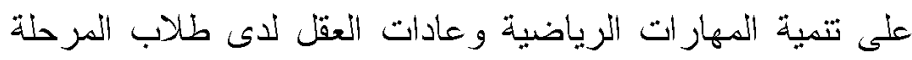

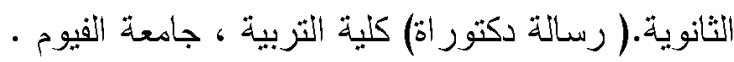

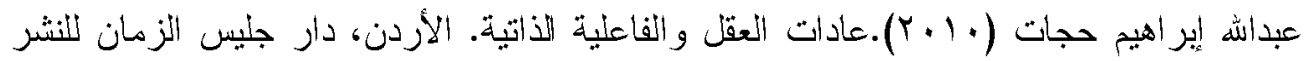
والتوزيع.

على حمد ناصر ريانى (Y ( Y). أثثر برنامج قائم على عادات العقل فى تتمية التفكير الإبداعى

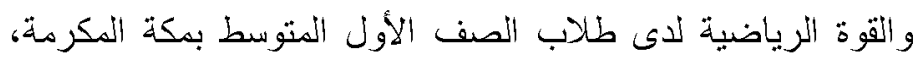

رسالة دكتور اه، جامعة أم القرى، المملكة العربية السعودية.

عماد عو اد سليمان (.Y.Y.Y). فاعلية توظيف استر اتيجية السقالات التعليمية في تدريس الرياضيات

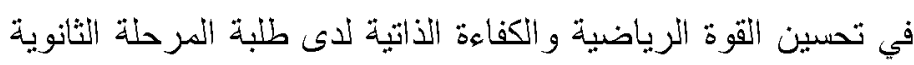

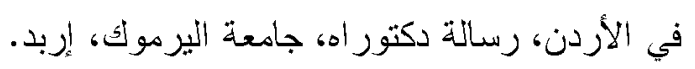

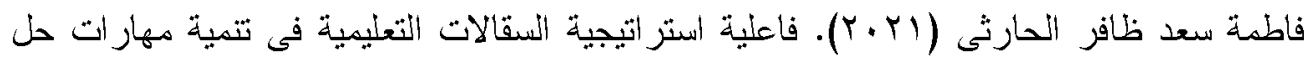

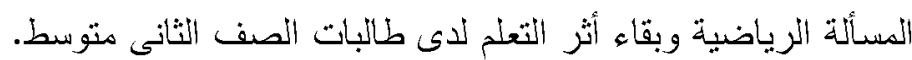

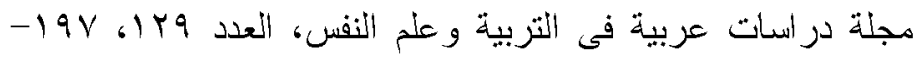

$$
\text { ror }
$$

فايز محمد منصور (Yl(Y). استز اتيجية مقترحة قائمةعلى العصف الذهني وحل المشكلات لتنميةعادات العقل ومهار ات التفكير الناقد في الرياضيات لدى تلاميذ التئ

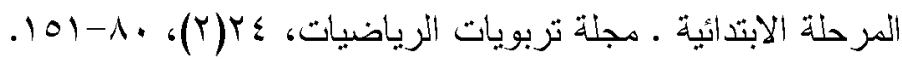

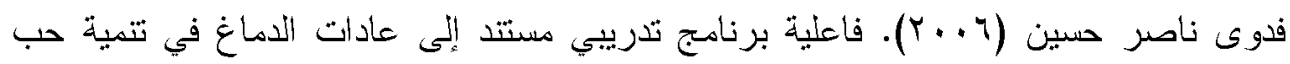

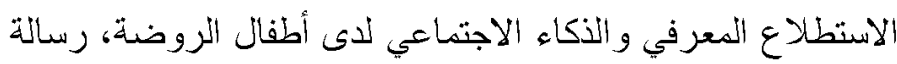

دكتور اه، جامعة عمان العربية للار استات العليا. 
استخدام استراتيجية السقالة التعليمية في تنمية عادات العقل المنتجة لدى طلاب المرحلة الثانوية أ/ أ/ محمد جاد الكريم عبدالعظيم محمود

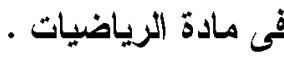

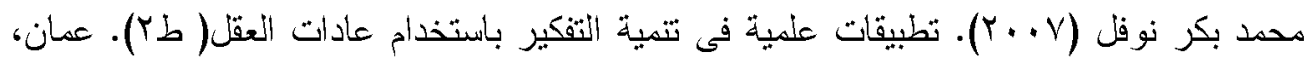

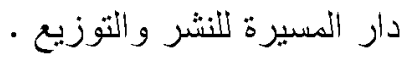

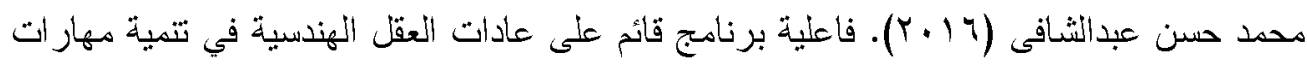

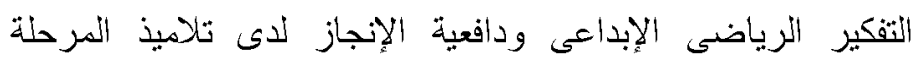

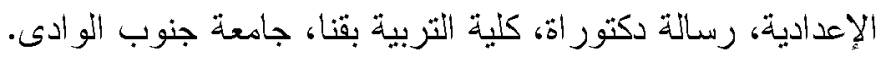
محمد عبد الله محمد الهاجرى (1) ( ب). فاعلية استر اتيجية الفصل المقلوب في تتمية عادات العقل

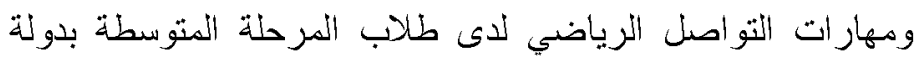

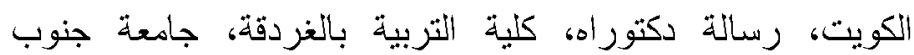

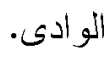

محمد محمود محد (11) (1). فاعلية استر اتيجية السقالات التعليمية فى تتمية التفكير التأملى

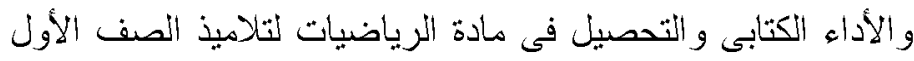

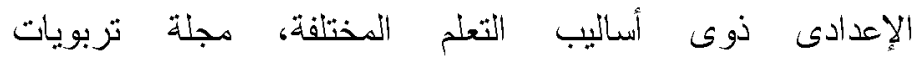

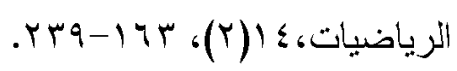

محمد مختار و نبيل جاد (• (ب). أثر التفاعل بين أنماط مختلفة من دعامات التعلم البنائية داخل

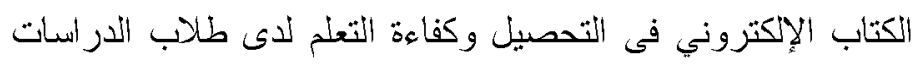
العليا بكليات التربية، مجلة دراسات تربوية واجتماعية، جامعة

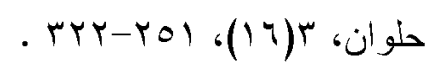

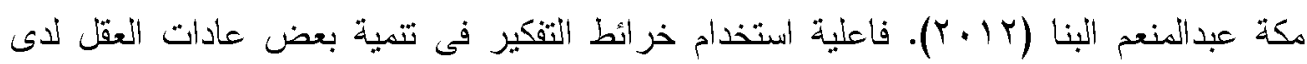

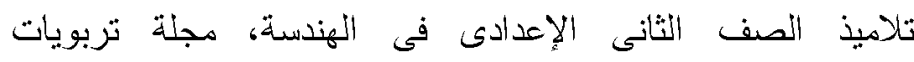

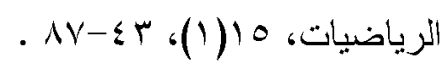

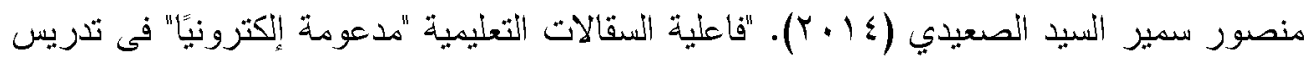

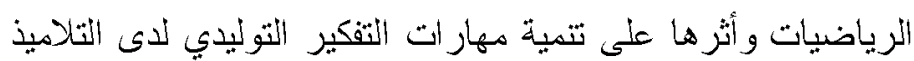

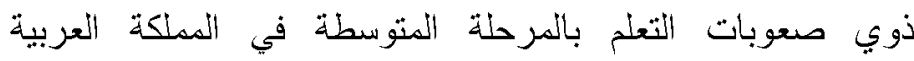

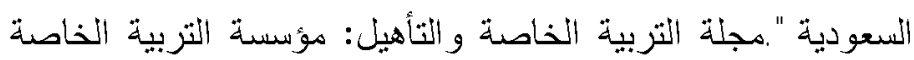

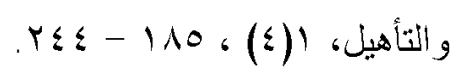

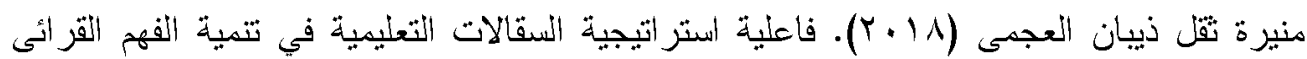

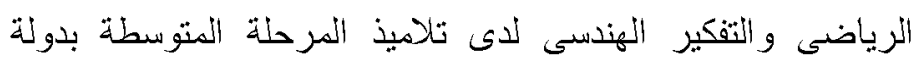

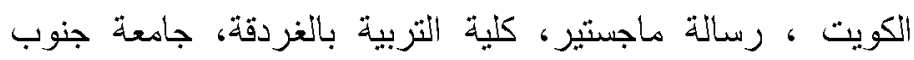
الو أدى. 
استخدام استراتيجية السقالة التعليمية في تنمية عادات العقل المنتجة لدى طلاب المرحلة الثانوية

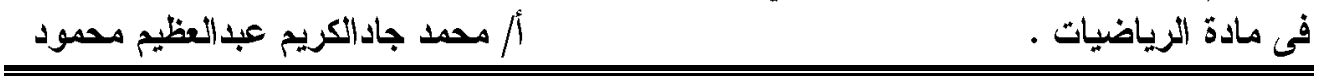

ناصر السيد عبد الحميد عبيدة (11) ب). استخدام أستوديو التفكير فى تدريس الرياضيات لتتمبة

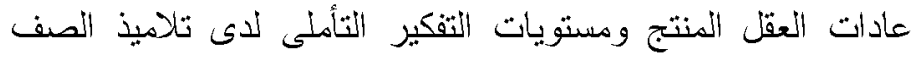

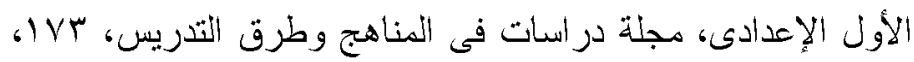

$$
.1 \leq V-1 \cdot r
$$

نهلة عبد المعطى الصدادق (10 + (10). تتمية بعض مهار ات التفكير المعرفية و عادات العقل باستخدام

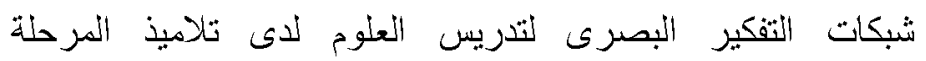

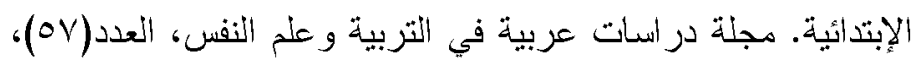

$$
.1 V \cdot-1 Y 4
$$

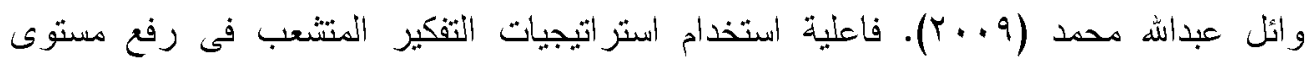
التحصيل فى الرياضيات وتتمية بعض عادات العقل لدى تلاميذ

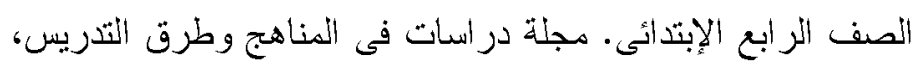

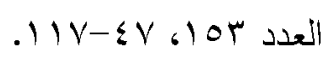

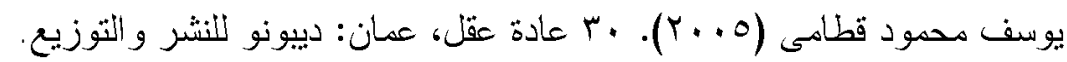
Adams, C. (2006). PowerPoint, habits of mind, and classroom culture. Journal of Curriculum studies, 38(4), 389- 411.

An, Yun- J 0.(2010). Scaffolding Wiki- Based, Ill- Structured Problem Solving in an Online Environment, MERLOT Journal of Online Learning and Teaching ,4(6), 723- 734.

Costa, A. L., \& Kallick, B. (Eds.). (2008). Learning and leading with habits of mind: 16 essential characteristics for success. ASCD.

Barlow, A. T., Gerstenschlager, N. E., Strayer, J. F., Lischka, A. E., Stephens, D. C., Hartland, K. S., \& Willingham, J. C. (2018). Scaffolding for Access to Productive Struggle. Mathematics Teaching in the Middle School, 23(4), 202- 207. 
استخدام استراتيجية السقالة التعليمية في تنمية عادات العقل المنتجة لدى طلاب المرحلة الثانوية

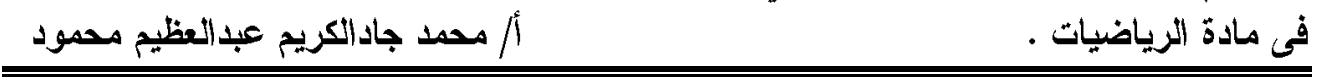

Berrett, D. (2012). Habits of mind: Lessons for the long term. Chronicle of Higher Education A, 1, A4.

Bolstad, F., Kanamaru, T., \& Tajino, A. (2011). Laying the groundwork for ongoing learning: A scaffolded approach to language education in Japanese elementary schools and beyond. In Second Language Studies: Acquisition, Learning, Education and Technology.

Costa, A. L., \& Kallick, B. (2005). Habits of mind. New York: spring press. Cuoco, A., Goldenberg, E. P., \& Mark, J. (2006). Habits of mind: An organizing principle for mathematics curricula. The Journal of Mathematical Behavior, 15(4), 375402.

Hu, Hosing-Wen.(2005). Developing Siblings and Peer Tutors to Assist Native Taiwanese Children in Learning Habits of Mind for Math Success (Doctoral dissertation). University of Massachusetts Amherst, United States.

Jacobbe, T., \& Millman, R. S. (2009). Mathematical habits of the mind for preservice teachers. School Science and Mathematics, 109(5), 298- 302.

Leikin, R. (2007, February). Habits of mind associated with advanced mathematical thinking and solution spaces of mathematical tasks. In Proceedings of the Fifth Congress of the European Society for Research in 
استخدام استراتيجية السقالة التعليمية في تنمية عادات العقل المنتجة لدى طلاب المرحلة الثانوية

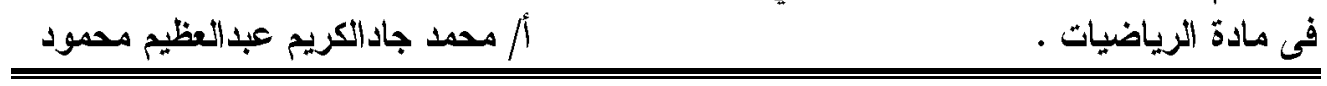

Mathematics Education(pp. 2330- 2339). Nicosia,,

Cyprus: Department of Education, University of

Cyprus.

Lewis, B. (2006). Scaffolding instruction strategies: Techniques to scaffold learning in the elementary classroom.

Magiera, M. T., Van den Kieboom, L. A., \& Moyer, J. C. (2013). An exploratory study of pre-service middle school teachers' knowledge of algebraic thinking. Educational Studies in Mathematics, 84(1), 93-113.

Mark, J., Cuoco, A., Goldenberg, E. P., \& Sword, S. (2010). Developing Mathematical Habits of Mind. Mathematics teaching in the Middle School, 15(9), 505- 509.

Marshall, A. (2004). High School Mathematics Habits of Mind Instruction:

Student Growth and Development, Unpublished Master's Thesis, Southwest Minnesota State University.

Sawyer, R. K. (Ed.). (2005). The Cambridge handbook of the learning sciences. Cambridge University Press.

Shapiro, A. M. (2008). Hypermedia design as learner scaffolding . Educational technology research and development, 56(1), 29- 44.

Shih, K. P., Chen, H. C., Chang, C. Y., \& Kao, T. C. (2010). The development and implementation of scaffoldingbased self- regulated learning system for $\mathrm{e} / \mathrm{m}$ - 
استخدام استز اتيجية السقالة التعليمية في تنمية عادات العقل المنتجة لدى طلاب المرحلة الثانوية

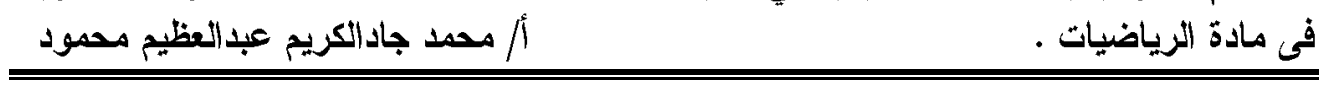

learning. Educational Technology \&

Society, 13(1), 80- 93.

Steinkuehler, C., \& Duncan, S. (2008). Scientific habits of mind in virtual worlds. J ournal of Science Education and Technology, 17(6), 530- 543.

Vago, D. R. (2014). Mapping modalities of self- awareness in mindfulness practice: a potential mechanism for clarifying habits of mind. Annals of the New York Academy of Sciences, 130ג1), 28-42.

Van Der Stuyf, R. R. (2002). Scaffolding as a teaching strategy. Adolescent learning and development, 52(3), 5- 18.

Van de Pol, J., Volman, M., \& Beishuizen, J. (2010). Scaffolding in teacher-student interaction: A decade of research. Educational psychology review, 22(3), 271-296. 